\title{
WestVirginiaUniversity
}

THE RESEARCH REPOSITORY @ WVU

Graduate Theses, Dissertations, and Problem Reports

2005

\section{Resistance of temporally controlled behavior to change}

\author{
Mirari Elcoro \\ West Virginia University
}

Follow this and additional works at: https://researchrepository.wvu.edu/etd

\section{Recommended Citation}

Elcoro, Mirari, "Resistance of temporally controlled behavior to change" (2005). Graduate Theses, Dissertations, and Problem Reports. 2215.

https://researchrepository.wvu.edu/etd/2215

This Thesis is protected by copyright and/or related rights. It has been brought to you by the The Research Repository @ WVU with permission from the rights-holder(s). You are free to use this Thesis in any way that is permitted by the copyright and related rights legislation that applies to your use. For other uses you must obtain permission from the rights-holder(s) directly, unless additional rights are indicated by a Creative Commons license in the record and/ or on the work itself. This Thesis has been accepted for inclusion in WVU Graduate Theses, Dissertations, and Problem Reports collection by an authorized administrator of The Research Repository @ WVU. For more information, please contact researchrepository@mail.wvu.edu. 


\title{
Resistance of Temporally Controlled Behavior to Change
}

\author{
Mirari Elcoro \\ Thesis submitted to the Eberly College of Arts and Sciences at \\ West Virginia University \\ in Partial Fulfillment of the Requirements for the Degree of
}

\section{Master of Science}

in

Psychology

\author{
Kennon A. Lattal, Ph. D., Chair \\ Karen G. Anderson, Ph. D. \\ Joseph R. Scotti, Ph. D. \\ Department of Psychology
}

Morgantown, West Virginia

2005

Keywords: temporal control, peak-interval procedure, resistance to change 


\section{ABSTRACT \\ Resistance of Temporally Controlled Behavior to Change}

\section{Mirari Elcoro}

To extend research on the relation between temporal control and resistance to change, the temporal location of response-independent food was examined in a modified peak-interval procedure (PIP) with pigeons. Sequences of the PIP consisted of 2, 3, 4 or 5 FI 30-s trials followed by a 90 -s peak trial, each separated by a 90 -s blackout. In different conditions, response-independent food was delivered within the first, last, or a randomly selected FI trial of each sequence. Overall, quarter-life values, peak times, and peak rates showed the highest decrease in temporal control relative to baseline when disruption occurred in the last FI trial. Delay of disruption gradients, constructed from each of these measures, were similar in form and function to delay of reinforcement gradients. 


\section{Acknowledgements}

I first thank Andy for his infinite patience and invaluable aid, not only during the preparation of this manuscript, but along my development as a scientist and as an independent thinker. I thank Karen G. Anderson for her constant availability, support, and wise advice. I thank Scotti for his amazingly thorough review of the manuscript and stimulating comments.

I thank my lab mates and friends: Megan Meginley, for her insatiable interest in research and for being able to make all of our conversations, concerning this thesis and other topics, so profound and enthralling; and, Raquel Alo, for her unconditional support, her knowledge of behavior analysis, and helpful comments about the analysis and interpretation of the results.

I also thank my friends Libby Tyner, for her advice on numerous aspects of the development of this manuscript; and Brian Ayotte for his knowledge of statistics and influential conversations about their adequacy in behavior analysis. 
Table of Contents

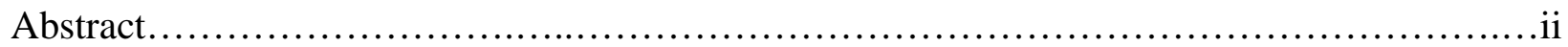

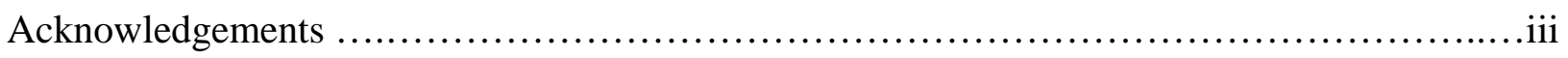

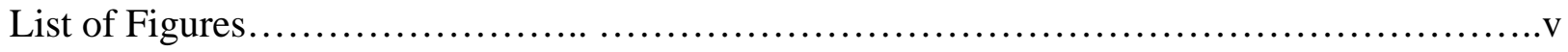

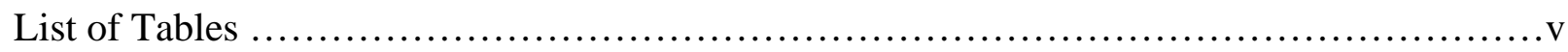

Resistance of Temporally Controlled Behavior to Change.....................................

Procedures and Measures of Temporal Control......................................2

FI schedules of reinforcement..........................................2

The peak-interval procedure (PIP) ....................................4

Procedures and Measures of Resistance to Change ..................................9

Temporal Control and Resistance to Change.....................................14

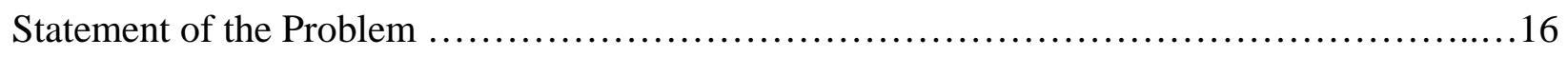

Method ...........................................................................

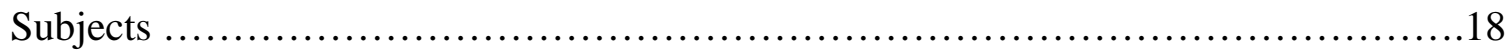

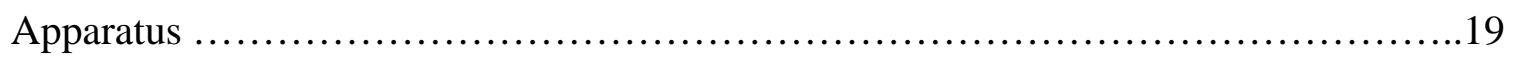

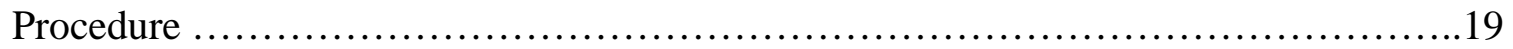

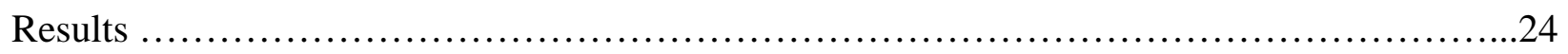

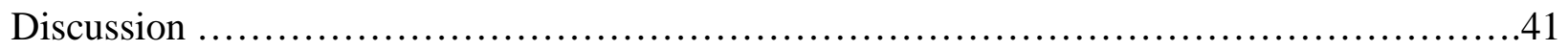

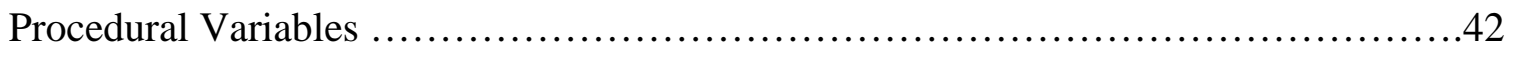

Temporal Control and Resistance to Change..................................47

Delay of Disruption Gradients..............................................52

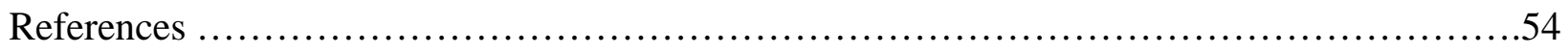




\section{List of Figures}

Figure 1: Diagram of a PIP........................................................... 5

Figure 2: Diagram of the Modified PIP.............................................22

Figure 3: Example of one Session................................................23

Figure 4: QL Values for FI trials.....................................................27

Figure 5: QL Values for Disrupted and Nondisrupted FI Trials............................29

Figure 6: QL Values for Initial condition................................................31

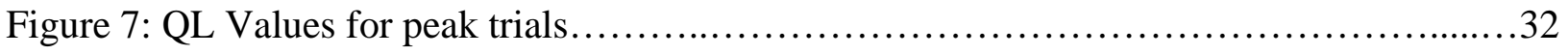

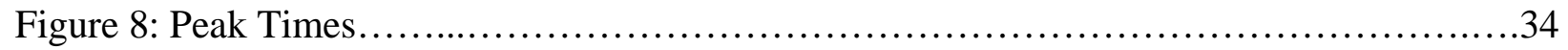

Figure 9: Peak Rates......................................................... 35

Figure 10: Delay of Disruption Gradients............................................

Figure 11: Scatterplots for Numbers of FI trials and QL Values.............................40 


\section{List of Tables}

Table 1: Conditions, Sessions, Average and Ranges for Response and Reinforcement Rates.....25

Table 2: Averages and Standard Deviations for each Condition and Each Pigeon................38 


\section{Resistance of Temporally Controlled Behavior to Change}

Temporal control has been defined as behavioral sensitivity based on temporal properties of stimuli (Catania, 1991). Such control is evidenced by differentiated operant responding after repeated exposure to periodic reinforcement during steady-state or transitional responding (Higa, 1998; Staddon, Chelaru, \& Higa, 2002). Many studies reported in the literature also refer to this effect as timing; however, hereafter in this review only the term temporal control will be used. The experimental procedure used to study temporally controlled behavior most relevant to the present study is the peak-interval procedure (PIP). This procedure involves a sequence of fixedinterval (FI) schedules followed by a period of extinction that is two to three times longer than the FI value (Meck, 2003).

The study of temporal control, particularly using the PIP, can be related to the concept of response strength or resistance to change. Resistance-to-change tests may involve a number of procedures, such as extinction, delivery of response-independent events, and pre-experimental feeding (Nevin, 1974). Responding in the presence of one of these tests is compared with prior baseline responding to assess response strength. As with other measures of response strength, the PIP involves the assessment of responding during extinction and can be used as a test of the resistance of behavior to change. Specifically, the PIP might be further exploited to examine the resistance to change of temporally controlled responding, a complex operant.

The general purpose of the present experiment is to investigate further this relation between temporal control and resistance to change. Therefore, the literature on both temporal control and resistance to change will be reviewed; these sections will focus on parameters of the procedures and measures of interest in each of the two areas. An integrative section to elaborate the relation between temporal control and resistance to change will follow. This last section of 
the review will lead to the specific purpose of the study, which is to assess effects of disrupting FI responding (and with it, presumably temporal control during the FI) on temporally controlled responding in the PIP. To do this, a procedure used in tests of resistance to change (the delivery of response-independent food) will be employed.

\section{Literature Review}

\section{Procedures and Measures of Temporal Control}

Several different procedures have been used to study temporally controlled responding, including FI schedules, the peak-interval procedure (PIP), a conditional discrimination procedure where the sample stimuli are temporal durations (Catania, 1970; Roberts, 1981); and the freeoperant psychophysical procedure (Stubbs, 1968), also known as the bisection procedure. Of these, the two most relevant to the present research will be reviewed in detail here.

FI schedules of reinforcement. An important component of the PIP is the simplest

procedure for studying temporal control, the FI schedule of reinforcement. In an FI schedule, the first response after a fixed period of time has elapsed is followed by the delivery of a reinforcer. After repeated exposure to this procedure, two patterns of responding have been observed. The FI scallop is defined by a progressive increase of response rate as the time for the delivery of the reinforcer approaches (Ferster \& Skinner, 1957). The break-and-run pattern is characterized by a short pause after the reinforcer delivery followed by more or less steady, high rate responding throughout the interval until the next reinforcer is delivered (Schneider, 1969).

The most basic measures of FI performance are response rates and postreinforcement pauses (PRPs). The former is typically an overall measure and therefore obscures response patterns that might reflect temporal control of responding. The PRP is the time from the offset of the previous reinforcer to the first response in the next interval (in some instances rather than the 
first response, some other response, for example, the fifth after the reinforcer, serves to demarcate the end of the PRP). The PRP is proportional to the value of the FI, that is, as the value of the FI increases, so does the PRP (Higa \& Pierson, 1998; Innis, Mitchell, \& Staddon, 1993).

The simplest way to observe and analyze temporal control in a FI schedule is by examining the distribution of responses across the FI, hereafter labeled a bin analysis. This analysis is conducted by dividing the FI into equal smaller intervals (hereafter bins; e.g., 1-s bins). Throughout a session, responses during the FI are accumulated in successive bins each time a new FI starts. The resulting distribution shows how responding changes during the course of the FI.

The most widely used measures of temporal control combine an analysis of PRP with the temporal distribution of responding. These combination summary measures are the quarter life (QL) and the index of curvature (IC). The QL is a quantitative summary index of different patterns resulting from exposure to an FI schedule (Gollub, 1964; Herrnstein \& Morse, 1957; Zeiler \& Powell, 1994). It is the percentage of the FI that has elapsed when $25 \%$ of the responses in that FI have occurred. A value lower than $25 \%$ indicates that relatively more responding occurred in the first quarter of the interval, the opposite is suggested when the value of the QL is greater than $25 \%$. The IC reflects the extent and direction of the difference between the data obtained in the distribution of responding across successive bins of the FI and a straight curve generated by a constant rate of responding across those bins (Fry, Kelleher, \& Cook, 1960; Gollub). Gollub defined the IC as the fraction resulting from the difference between the area under the constant rate cumulative curve and the area under the obtained curve, divided by the area under the constant rate cumulative curve. 
There is a high positive correlation between the QL and the IC. Both provide an adequate summary of temporal control and can be used interchangeably (Gollub, 1964). The QL and the IC are both independent of average rate of responding. The IC is sensitive to fluctuations in response patterns (Miller, Brodkorb, \& Branch, 2001). At the same time, the IC has been shown to be inappropriate when analyzing intervals with few responses (Baron \& Leinenweber, 1995). Odum and Schaal (2000) also pointed out that the IC was not sensitive enough to assess disruption of temporal control (induced by morphine) in FI schedules of reinforcement. In light of the aforementioned limitations of the IC, and because the QL has been shown to be a useful tool for assessing temporal control (e.g., Freeman \& Lattal, 1992), the latter measure was employed to analyze FI data in the present experiment.

The peak-interval procedure (PIP). The PIP is diagrammed in Figure 1. The PIP consists of a combination of a block of FIs (hereafter, FI trials) correlated with a discriminative stimulus (light or tone) followed by a single peak trial. Each trial is separated by a blackout or intertrial interval (ITI), during which all the chamber lights are extinguished. The peak trials are periods of extinction (i.e., nonreinforcement), typically longer than the individual FI trials and correlated with the same discriminative stimulus as that used in the FI trials. Peak trials are used to test temporal control acquired during responding on the FI trials contained within the PIP. This procedure allows the measurement of the decreasing response pattern after the FI value that otherwise is truncated in a simple FI schedule (Grace \& Nevin, 2000). A typical PIP sequence consists of a variable number of FI trials followed by a single peak trial. Thus, during an experimental session, there might be a total of 18 FI trials and 6 peak trials, each trial separated by an ITI (Drew, Fairhurst, Malapani, Horvitz, \& Balsam, 2003; Grace \& Nevin). 


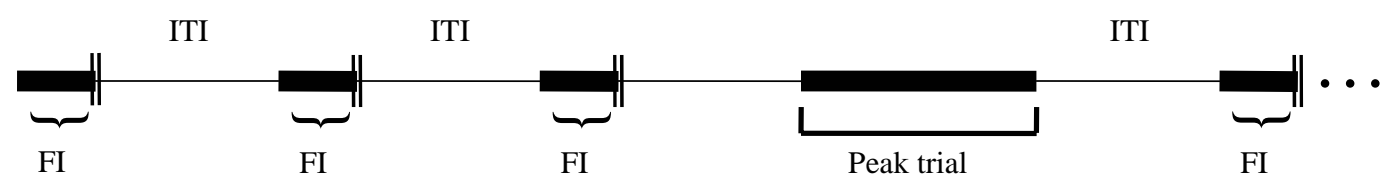

Figure 1. Illustrative PIP sequence of three FI trials per peak trial, all separated by an intertrial interval (ITI). Peak trials and ITIs are longer than the FI trial duration. The double-lined columns at the end of each FI trials represent reinforcer delivery upon the first response after the FI duration. 
Most of the studies that utilize the PIP include in the analysis data only from the peak trials and not from the FI trials (e.g., Abner, Edwards, Douglas, \& Brunner, 2001; Drew et al., 2003; Malapani \& Rakitin, 2003; Zeiler \& Powell, 1994). In the present experiment, however, data from both the FI and peak trials were analyzed and reported to examine disruption within the FI trials. The FI data were analyzed using the bin analysis and the QL index, as described above. Temporal control during the peak trials was assessed with the bin analysis and QL index, as well as with two additional measures, the peak time and peak rate.

The peak time is an absolute measure of temporal control and it is defined as the temporal point within the peak trial where the highest response rate occurs (Abner et al., 2001; Drew et al., 2003; Malapani \& Rakitin, 2003; Meck, 1996, 2003). To locate the peak time, the peak trial is divided in bins of the same duration as those used in the FI trials that precede the peak trials and the bin that contains the highest response rate defines the peak time. Temporal control is said to be most accurate when the peak time is equal to the FI value.

Although the above definition of peak times is consistent across studies, the calculation of this measure varies. For example, Cheng and Roberts (1991) and Grace and Nevin (2000) used a trimmed median method (i.e., the median of the cumulative response distribution was first determined, then responses after twice that median were excluded from that distribution, so a second median was calculated from the trimmed distribution. This process was repeated until no difference was found between the medians). Drew et al. (2003) employed a model that adjusted data on a trial-by-trial basis and excluded trials with poor goodness of fit. In the present research the mode of the response distribution from one session was used, because this measure seems to fit more accurately with the definition of the peak time. This calculation also involves less 
manipulation of the data than the methods described above, with the benefit that data remain closer to their raw form and that no trials are excluded from the analysis.

Shifts in the peak time from a baseline during a manipulation of some aspect of the PIP provide a relative measure of temporal control. Manipulations, such as drug administration (e.g. Abner et al., 2001; Drew et al., 2003; Malapani \& Rakitin, 2003; Meck, 1996), change both the direction of the peak time (either a rightward or leftward shift relative to a baseline condition) and also the value of the shift, which is the difference between baseline peak time and the peak time obtained after the change is introduced (e.g., after injection of a drug). Direction and value of peak time shifts are indices of the degree of disruption of temporally controlled behavior by the independent variable. Findings in which response distributions of peak trials are shifted to the left (relative to baseline response distributions) have been interpreted as early responding in the peak trial (Odum, Lieving, \& Schaal, 2002). According to Odum et al., evidence of rightward shifts of response distributions have been interpreted as delayed (or late) responding in the peak trial, relative to baseline responding.

Another measure of temporal control obtained in the peak trial of a PIP is the peak rate. This measure is more sensitive than overall response rate to changes in temporal control caused by disruptive tests (Grace \& Nevin, 2000). The peak rate is the response rate at the peak time.

Figure 1 reveals several parameters of the PIP that might be varied, such as the number of FI trials, which might in turn affect the accuracy of temporal control. Two ITI parameters that might affect temporal control are the duration and constancy/variability of the ITI. Grace and Nevin (2000) used a fixed 20-s ITI within both a PIP with an FI $10 \mathrm{~s}$ and a 30-s peak trial and PIP with FI 30 s and 90-s peak trial, while Drew et al. (2003) used a variable ITI with a 90-s mean. Abner et al. (2001) found a re-initiation of responding by the end of the peak trial when 
ITIs were longer than three times the FI. There is, however, a paucity of direct comparisons of the effects of different values of these parameters on temporal control, leaving generally unanswered their role in establishing and maintaining temporal control in the PIP.

An unexplored aspect of the development of temporal control as indexed by the PIP is the use of pretraining sessions consisting only of FI trials prior to training in the PIP (Grace \& Nevin, 2000). The PIP can be implemented with or without FI pretraining, that is, with or without a series of sessions involving simple exposure to the FI schedules that will be included subsequently as part of the PIP. The inclusion or exclusion of pretraining depends on which aspect of temporal control is relevant to the study. If the focus of the study is the development of temporal control in the PIP, then pretraining is not used. When the focus is on established temporal control, as in the present experiment (specifically the disruption of temporal control), FI pretraining is utilized.

The PIP has also been employed to compare effects of two different FI values within a session. For example, Drew et al. (2003) used rats trained on both FI 12-s and FI 36-s schedules preceding peak trials of, respectively, 36 and $288 \mathrm{~s}$. Each PIP was correlated with a different discriminative stimulus. When responding (i.e., nose poking) was stable in both PIPs, temporal control was compared. Response rates were higher on the PIP with FI $12 \mathrm{~s}$ and 36-s peak trial. Also, temporal control was more variable on the PIP with FI 36 s and 288-s peak trial.

The fact that more variability was found in the PIP with longer temporal parameters may be due to the scalar property (Gibbon, 1977) of temporal control. This property is described by Weber's law (i.e., the mean and standard deviations of temporal estimates are proportional to the interval in the schedule). Longer intervals produce more variable distributions (Gibbon) of responding and therefore weaker stimulus control than shorter durations (Lieving, 2003). 
According to Lieving, a longer interval could be less resistant to change because of weaker stimulus control due to a temporal control property (the scalar property) and not because of a lower rate of reinforcement.

Attempts to disrupt temporally-controlled responding developed in FI schedules and the PIP may be conceptualized as involving resistance of the responding to change, a phenomenon that has been studied extensively with simple operants. There are a few experiments that have examined the relation between these two research areas, and this relation is reviewed in the next section.

Procedures and Measures of Resistance to Change

Resistance to change was proposed by Nevin (1974) as a procedure for indexing response strength. Nevin and his colleagues (1974 et seq.) have gathered sufficient empirical evidence to show that rate of reinforcement seems a more relevant dimension of resistance of responding to change than response rate, as Skinner (1938) initially proposed.

The study of resistance to change involves the systematic introduction of a new variable during a steady-state baseline in, typically, a two-component multiple schedule with different conditions of reinforcement in each component (Nevin, 1974, 1988). This new variable has included prefeeding, response-independent events in the blackout of a session, or extinction. Resistance of responding to change is measured by examining whether, and if so, how, responding maintained by the different contingencies is disrupted. A response is more resistant to change when it is maintained by a schedule arranging more frequent reinforcement (rich schedule) compared to a schedule arranging less frequent reinforcement (lean schedule). The most common index of resistance to change is the percent change of responding when the 
disrupter is present from a baseline condition without the added disrupter. The smaller percent change from the baseline, the more resistant the responding is to change.

In the present experiment, the PIP is conceptualized as a test of resistance to change, not only because it contains repeated extinction trials, but because the procedure itself implies repeated training that equals the generation of a baseline condition. Most of the studies that use the PIP to study temporal control include the introduction of a new variable to a baseline condition to generate changes. For example, baseline responding is obtained in PIP and drugs are administered to observe the changes in the patterns of responding (e.g., Abner et al., 2001; Drew et al., 2003; Malapani \& Rakitin, 2002; Meck, 1996). The drugs employed in these studies are administered prior to an experimental session, the same way prefeeding is executed in a resistance to change test.

Some drugs at specific doses may be construed as disrupters because of their comparable effects on responding relative to those of disrupters employed in resistance to change tests (Lieving, 2003; Pitts \& Febbo, 2004). For example, using pigeons as subjects, Odum and Schaal (2000) found that morphine produced similar decreases in temporal control to those found by Stubbs, Vautin, Reid, and Delehanty (as cited by Odum \& Schaal) with nonpharmacological disrupters. Additionally, systematic effects on temporal control in rats have been observed after administration of drugs that affect the cholinergic (Meck \& Church, 1987) and the dopaminergic systems (Meck, 1996).

The gap procedure (Aum, Brown, \& Hemmes, 2004; Buhusi, 2003) is another way to study disruption of stable responding in a PIP. The gap is a break in the trial accompanied by an extraneous stimulus (tone or light) introduced during the peak trials in a PIP. In a study by Aum et al., pigeons were trained in a PIP with FI 30 s and 90-s peak trials, and an ITI of variable 
duration (with a mean of $22.5 \mathrm{~s}$ ). The gap was a darkened keylight that lasted $6 \mathrm{~s}$ and occurred either $3 \mathrm{~s}$ (early), $9 \mathrm{~s}$ (middle) or $15 \mathrm{~s}$ (late) from the onset of a peak trial. With each of the three gap placements, Aum et al. found that the peak times shifted to the right when compared to peak times in a baseline condition. Rightward shifts in the peak times were proportional to the temporal location of the gap. Particularly, when the gap was introduced early in the peak trial (i.e., $3 \mathrm{~s}$ after the onset of the trial) the largest rightward shift in the peak time was produced. As previously stated, to the extent that some drugs at specific doses serve as disrupters, the gaps in this procedure can also be conceptualized as disrupters of stable responding. The gaps are analogous to the delivery of response-independent events in a resistance-to-change test.

The procedures used to disrupt responding most relevant to the present study are extinction (defined as elimination of reinforcement) and the delivery of response-independent food. As noted in the introduction, extinction as a test of resistance to change is relevant to the present study because it defines the peak trial. In the PIP, because there are repeated cycles of FI trials and extinction, unlike the complete removal of reinforcement in conventional resistance to extinction tests, extinction is employed intermittently to test temporal control of responding. In the PIP, the number of FI trials preceding the peak trials could be correlated with the extent of temporal control. Temporally controlled responding after many, as opposed to few, reinforcers might therefore be more resistant to change because each additional FI trial brings with it an additional reinforcer, thus increasing the total number of reinforced trials.

The delivery of response-independent events, typically food, is the other resistance to change procedure relevant to the present study. Response-independent food deliveries used to disrupt baseline responding commonly have been introduced during a blackout (ITI) between 
components of the multiple schedule (cf., Nevin, 1974). Such delivery, however, could occur during the components rather than between them (cf., Nevin, Tota, Torquato, \& Shull, 1990). The selection of response-independent food delivery over other resistance-to-change tests, such as prefeeding, was based on the observation of some researchers (e.g., Lieving, 2003) that more reliable results of disruption of temporally controlled responding have been obtained with response-independent food delivery than with prefeeding. Furthermore, there is evidence, described below, to suggest that response-independent food during an FI schedule disrupts characteristic FI patterns and therefore perhaps temporal control as measured in other ways.

Lattal and Bryan (1976) studied the disruption of temporally controlled responding during an FI 5-min schedule of reinforcement with pigeons as experimental subjects. In Experiment 1, the pattern of positively accelerated keypecking resulting from extended training on an FI schedule was disrupted by superimposing response-independent food arranged according to a variable-time (VT) schedule as an experimental condition that was in effect for several experimental sessions until stability was assessed by visual inspection. Several different VT values $(2.5,1.5$ and $0.5 \mathrm{~min})$ similarly disrupted FI patterns, which changed from positively accelerated during the FI to more linear during the superimposed VT schedules. This result was observed by the patterns of cumulative records depicting more linear responding and also by a decrease in QL values relative to baseline QL values for the sessions in which VT schedules were superimposed.

In their Experiment 3, Lattal and Bryan (1976) disrupted positively accelerated patterns of responding maintained under FI schedules of reinforcement by superimposing responseindependent food arranged according to a fixed-time (FT) schedule of reinforcement. For one pigeon an FI 3 min was disrupted by an FT 1 min, and for another pigeon, an FI 1 min was 
disrupted by an FT 0.33 min. Responding was positively accelerated after each disrupter and reinforcer delivery.

Lattal and Bryan's (1976) results suggest the following about disruption of temporal control. First, the temporal distribution of reinforcers (e.g., FI schedule) determines response patterns. Second, the disruption of temporally controlled responding does not directly depend on the response-reinforcement relation (Experiment 3). Third, the pattern of temporally controlled responding may change as a function of the distributions of response-independent events (e.g., VT and FT schedules of disruption produced different changes in an FI schedule baseline). A comparison of Lattal and Bryan's first and third experiments shows how temporally controlled behavior is differentially resistant to different schedules of disrupters.

In the previously described study by Aum et al. (2004), the temporal location of the gap in the peak trial had a differential effect on established temporal control. Even though their location of disrupters was not during the FI (as in Lattal and Bryan, 1976), but during the peak trial, their results are relevant to the idea that temporal location of response-independent events or disrupters, differential affects temporally controlled behavior.

The idea that the temporal distribution of disrupters affects established responding was further explored by Lattal and Abreu-Rodrigues (1997). In two preliminary experiments with pigeons as experimental subjects (Experiments 1 and 2), Lattal and Abreu-Rodrigues disrupted stable VI (300-1800 s) responding with a constant FT 150 s schedule of food delivery. It was not possible to accurately relate the changes observed in rate and pattern of responding in the VI schedule to the value of the VI, the FT or any combination of thereof. The disrupters created new temporal relations that controlled behavior and disrupted the previous VI performance. The 
temporal distribution of disrupters served a discriminative role that exerted control over VI responding.

\section{Temporal Control and Resistance to Change}

Grace and Nevin (2000) examined the relation between response strength and temporally controlled responding employing the PIP and three resistance-to-change tests (responseindependent food delivery, prefeeding, and extinction) with pigeons. They used a twocomponent PIP with FI 20-s, 60-s peak trial, and 20-s ITI. One component had a small reinforcer magnitude (1.5 s access to grain) and the other component had a large reinforcer magnitude (4.5 s access to grain). Response-independent food delivery consisted of VT 7.5-s schedule during the ITI. This resistance to change test produced slight increases in the peak times of the largereinforcement component relative to baseline responding. The peak times on the smallreinforcement component were slightly increased, but only when prefeeding and extinction were in effect. Peak rates decreased in both components when the three resistance-to-change tests were in effect. Changes relative to baseline were assessed during the first five sessions after the disrupter was introduced.

A second experiment by Grace and Nevin (2000) involved a two-valued PIP, that is, a concurrent PIP with FI 10 s and 30-s peak trials and a PIP with 30-s and 90-s peak trials, with 20-s ITI in both cases. By thus decreasing the FI value (from $30 \mathrm{~s}$ to $10 \mathrm{~s}$ ) they increased the reinforcement rate. After responding stabilized, the same three resistance-to-change tests described in the previous paragraph were implemented. Responding maintained on the PIP with FI $10 \mathrm{~s}$ and 30-s peak trials was more resistant to change. Lieving (2003) noted a potential problem with the findings of Grace and Nevin's second experiment: reinforcement rate is confounded with the interval to be timed. As noted earlier in this review, the scalar property of 
temporal control suggests that the mean and the standard deviations of temporal estimates are proportional to the interval to be timed (Gibbon, 1977).

Using a free-operant psychophysical procedure (FOPP), Lieving (2003) examined the disruption of temporally controlled responding by the delivery of response-independent food and prefeeding with pigeons. Lieving employed two response keys that could be transilluminated either red or green, where green was correlated with a VI 120-s schedule and red with a VI 30-s schedule. There were 15 trials of each type (red and green) separated by a 15-s blackout. During the first $25 \mathrm{~s}$ of each trial, responding on the left key was reinforced and during the last $25 \mathrm{~s}$ of the trial, responding on the right key was reinforced. The transition from reinforcing left to right key responding was not signaled. The measure of temporal control (ET50) was the point at which the responding reliably shifted from the left to the right key. The question of interest was the extent to which temporal control under the red and green keylights would be disrupted by either prefeeding (i.e., 22.5-82.5 $\mathrm{g}$ of food, $30 \mathrm{~m}$ prior to experimental session) or responseindependent food delivered according to a VT 5-, 15-, or 30-s schedule during a blackout between the two key color presentations.

Lieving's (2003) findings using response-independent food delivery as the disrupter replicated and extended those obtained by Grace and Nevin (2000). Lieving used more than one VT value (Grace and Nevin only used one) and found that responding was more disrupted by higher rates of response-independent food delivery. In a second experiment, Lieving varied the reinforcer duration in the FOPP. Green keylight pecking produced 1-s access to grain, while pecks on the red keylight produced 6.5-s access to grain. When employing response-independent food to disrupt stable responding, temporally controlled behavior was more resistant when the duration of the reinforcer was $6.5 \mathrm{~s}$. 
With prefeeding as a disrupter in the FOPP, Lieving (2003) found that prefeeding effects on temporally controlled responding were unclear (see also Ferguson and Paule, 1995). Contrariwise, Plowright, Church, Behnke, and Silverman (2000) and Roberts (1981) found consistent disruption of temporally controlled responding with prefeeding. The consistent disruption was reflected by a rightward shift on the peak times when prefeeding was introduced in baseline disruption. The peak times after disruption were $2-3 \mathrm{~s}$ longer than the peak times during the baseline. Two potential variables could be involved in the explanation of the differences between the results with prefeeding. The first is the location where the prefeeding is conducted and the second is the quality of the food utilized in the test. Although Fergurson and Paule (1995) and Lieving (2003) performed prefeeding in the housing cages with pigeon chow, Plowright et al. (2000) and Roberts (1981) performed the prefeeding in the feeders of the operant chambers with the same food used as reinforcers, that is, pellets of pigeon chow.

In light of the lack of evidence of a systematic effect of prefeeding on temporally controlled responding, response-independent food will be used as the resistance-to-change test to examine the disruption of temporal control maintained on a PIP. Reliable disruption has resulted when the disrupters were delivered within the FI trials (Lattal \& Bryan, 1976). Changing the context where the disruption occurs and separating the disruption from the experimental session by adding a prefeeding session (even when prefeeding occurs in the same operant chamber, it occurs before the experimental session starts) makes response-independent food delivery a potentially more reliable test of resistance of temporally controlled responding to change.

\section{Statement of the Problem}

Temporal control is defined in terms of differentiated responding as a consequence of the temporal properties of stimuli (Catania, 1970). Responding maintained in a PIP may be 
considered a complex operant because the behavior in its components is comprised of multiple individual responses organized in a temporally extended pattern (cf., Hawkes \& Shimp, 1975). To further examine the structure of such complex operants and their cohesiveness, their resistance to change will be tested through the delivery of response-independent food. The present experiment was designed to examine effects of different temporal locations of disrupters during responding within a PIP. Unlike many previous studies of response strength, including those of Grace and Nevin (2000) and Lieving (2003), the response-independent food will be presented within each FI, a procedure that previously has been shown to disrupt temporally controlled responding (Lattal \& Bryan, 1976). Three different locations of disrupters concerning the FI trials preceding a peak trial will be studied as different conditions of the experiment: the disrupter will be placed randomly in one of the FI trials that precede a peak trial, during the first FI trial preceding a peak trial, and during the last FI trial preceding a peak trial.

Throughout much of the early history of the experimental analysis of behavior, the primary dependent variable used to assess resistance of behavior to change was the rate of responding (see Ferster \& Skinner, 1957). Nevin (1974) and his colleagues, however, isolated rate of reinforcement as a primary determinant of response strength. Most studies of resistance to change involve multiple schedules of reinforcement (typically with one component correlated with a rich and the other with a lean schedule of reinforcement; Nevin, 1988). Despite many studies of response strength of simple operants, only a few studies have investigated the resistance of complex operants to change, such as those exemplified by temporally organized behavior.

By manipulating rate of reinforcement, Grace and Nevin (2000) examined the resistance of temporally controlled responding to change (by extinction, prefeeding and response- 
independent food delivery) maintained during a PIP. Lieving (2003) critiqued Grace and Nevin's logic of manipulating rate of reinforcement by changing the duration of the FI in the PIP pointing out that the FI duration and reinforcement rate were confounded, as noted in the literature review. Lieving then further examined the relation between temporal control and response strength using a procedure (the FOPP) that allowed the manipulation of rate and duration of reinforcement without altering the intervals involved.

The PIP was selected as the procedure for establishing and assessing temporal control because (a) it maintains a complex operant; (b) it has been shown previously by Grace and Nevin (2000) to be, potentially at least, differentially sensitive to other resistance-to-change tests; and (c) because it is, in fact, a resistance-to-change test that contains repeated periods of extinction (the peak trials) as the means of testing resistance of temporally controlled responding maintained during the preceding FI trials.

Although the focus of the experiment was on the resistance of temporally organized behavior to change, effects of the disrupters were not only be reflected in responding during the peak trials, but also in FI responding. Thus, the experiment also examined the disruption of FI responding by response-independent food at different locations within the FI (cf. Lattal \& Bryan, 1976).

\section{Method}

\section{Subjects}

Four mature male White Carneau pigeons, with prior experimental history with various positive reinforcement schedules (subjects 510,553, 778, and 738), were maintained at approximately $80 \%$ of their ad-libitum weight. Subject 553 died after the baseline recovery was completed for the first condition of the experiment. All subjects were housed individually with 
free access to water and health grit. Illumination $(12 \mathrm{~h}$ light/dark cycle $)$ and temperature $\left(24^{\circ} \mathrm{C}\right)$ were maintained at constant values.

\section{Apparatus}

Two operant conditioning chambers were located in a sound-attenuating enclosure. Each chamber work area was $32 \mathrm{~cm}$ long by $30 \mathrm{~cm}$ high by $30 \mathrm{~cm}$ wide. An aluminum work panel comprised one wall of the chamber. One $2.54-\mathrm{cm}$ diameter response key was centered on the midline of the work panel, and was transilluminated by a white light. Reinforcement was $3 \mathrm{~s}$ of access to mixed grain from a hopper placed behind a $4.5-\mathrm{cm}$ square feeder aperture centered on the aluminum panel and located on the midline of the work panel $9 \mathrm{~cm}$ from the floor. The hopper was raised into the aperture, which was illuminated by a white light during reinforcement. General chamber illumination was provided by a houselight located on the top of the chamber. A ventilation fan and a white noise generator were used to mask extraneous noise. Experimental events and data were controlled and recorded with Med-Associates ${ }^{\circledR}$ programming and interfacing.

\section{Procedure}

Experimental conditions. Sessions occurred once per day, seven days a week at approximately the same time during the light phase of the illumination cycle. Weights of each subject were measured before and after each session. Postsession feeding occurred when weights after the session were below previously established $80 \%$ level of food restriction, and food amounts were provided accordingly to maintain the appropriate weight. Pretraining was followed by training on a baseline PIP. Three disruption conditions were conducted for each subject in varying order. Each disruption condition remained in effect until stability was reached and was separated by baseline recovery. Each condition is described below. 
Pretraining. Each subject was first exposed to 24 - 27 sessions of an FI 30 s. Each pretraining session was composed of 40 FI 30 s segments until 40 reinforcers were earned. Pretraining established temporal control of FI responding and remained in effect until QL values were greater than $35 \%$. Once pretraining was completed, exposure to training in the PIP commenced.

Baseline- PIP. Once QL values obtained for responding under the FI pretraining were stable upon visual inspection, a modified PIP was implemented. This procedure is shown in Figure 2. The original PIP described by Catania (1970) was modified so that instead of separating each trial of the procedure by an inter-trial interval (ITI), as described before and as depicted in Figure 1, trials were compressed. That is, FI trials immediately followed one another after the preceding reinforcer until all were completed. This in turn was followed immediately by the peak trial. The unit comprised of a number of FI trials and a peak trial was labeled a sequence.

Each session was comprised of 12 sequences, each separated by an intersequence interval (ISI), during which the chamber was dark. The FI trials were correlated with the center white keylight and were separated by reinforcer delivery. The peak trials were correlated with the same center white keylight as a discriminative stimulus, and were followed by an ISI. Thus, the modified PIP contained FI 30-s trials, followed by a 90-s peak trial, which in turn was followed by a 90-s ISI. An example of how the sequences were arranged within a complete session is shown in Figure 3. A session was comprised of three blocks. Each block contained a sequence of 2, 3, 4, and 5 individual FI trials. Within a block, the order of the number of FI trials in the sequence was determined randomly without replacement. Each session lasted for approximately $57 \mathrm{~min}$. A total of 42 reinforcers was delivered for each session in the baseline condition. 
Disruption conditions. Response-independent food was delivered within some FI trials to disrupt the response pattern obtained in the FI. For all FI trials, this procedure was accomplished by dividing the FI $30 \mathrm{~s}$ into 1-s bins, and then randomly selecting one of them for food delivery. Only one disrupter per sequence was delivered, for a total of 12 disrupters per session. The three conditions differed according to the temporal location of the delivery of response-independent food within a sequence.

One condition, labeled Initial, involved delivering response-independent food ( $3 \mathrm{~s}$ access to grain while houselight and keylight were still on for the current FI trial) as previously described, only in the first FI trial of each sequence of the session. The second condition, labeled Random consisted of randomly selecting one of the FI trials in a sequence and delivering response-independent food within the selected FI trial. During the condition labeled Final, response-independent food was delivered in the last FI trial of each sequence. The order of the three conditions just described was different for each pigeon and is shown in the second column of Table 1, along with the number of sessions per condition (shown in the third column of Table 1). Each condition was followed by baseline recovery.

A session consisted of 12 sequences. A minimum of 13 sessions were conducted during each condition and conditions were changed only when QL values for FI trials and QL values for the first third of the peak times were stable. A condition was considered stable when (a) the average QL value for the first half and the last half of the six last sessions was no more than +/- 5 $\%$ of the total average QL value observed during those six sessions, and (b) no systematic trends (ascending or descending) in the QL values were observable over the last six days. 


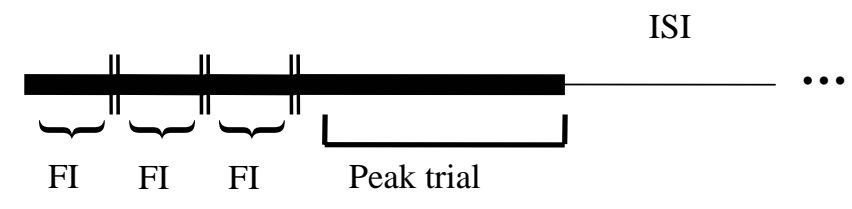

Figure 2. Example of one sequence of the PIP in the present experiment. This particular sequence shows three FI trials, separated by reinforcer delivery (double-lined columns) followed by a peak trial, followed in turn by an inter-sequence trial (ISI). Peak trial and ISI are three times as long as the FI duration. 


\section{Block}

1. FI/FI/-peak-ISI $\rightarrow$ FI/FI/FI/-peak-ISI $\rightarrow$ FI/FI/FI/FI/-peak-ISI $\rightarrow$ FI/FI/FI/FI/FI/-peak-ISI $\rightarrow$

2. FI/FI/FI/-peak-ISI $\rightarrow$ FI/FI/FI/FI/-peak-ISI $\rightarrow$ FI/FI/FI/FI/FI/-peak-ISI $\rightarrow$ FI/FI/-peak-ISI $\rightarrow$

3. $\quad$ FI/FI/FI/FI/-peak-ISI $\rightarrow$ FI/FI/FI/FI/FI/-peak-ISI $\rightarrow$ FI/FI/-peak-ISI $\rightarrow$ FI/FI/FI/-peak-ISI

Figure 3. Example of one session of the PIP in the present experiment. It comprises three blocks. Each block contains a sequence of 2,3,4, and 5 individual FI trials. The order of the number of FI trials varies in a random (without replacement) manner. 


\section{Results}

For Pigeon 553 only data from the Final condition and its corresponding baseline reversal are presented due to the pigeon's death at that point in the experiment. Average response rates (total number of responses during FI and peak trials divided by the total time minus ISI and reinforcement times) and reinforcement rates (total number of reinforcers divided by the time spent on the FI trials) are shown in the fourth and fifth columns of Table 1. Data are presented from the last six sessions of each experimental condition. Reinforcement rates showed that the actual number of reinforcers earned within a session was roughly equal to the number programmed (i.e., approximately two reinforcers per minute). When compared to previous baselines, average response and reinforcement rates decreased during most the disruption conditions. Informal webcam viewings revealed that all pigeons consumed response-independent food.

The QL values for the FI trials were calculated by pooling the data from successive 1-s bins during all the FI trials for each session, and then locating the percentage of the trial in which $25 \%$ of the total number of responses were allocated. Figure 4 shows the QL values for the FI trials of the last six sessions of each condition. Overall, when compared to the preceding baseline QL values, the Initial condition produced no changes; the Random condition produced slight decreases; and the Final condition produced slight decreases in Pigeons 553, 510 and 778, but not in Pigeon 738 (a slight increase in QL was observed instead). In general, baseline QL values tended to increase after returns to the baseline condition. For Pigeon 738, data for the disrupted FI trial were not collected for the Initial condition due to a mistake in data recording, which resulted in incomplete data only for FI trials (disrupted FI trials were not recorded, only nondisrupted FI trials) for that condition, not for the peak trials. After this condition, the mistake 
Table 1

Experimental conditions in order of presentation (second column). Number of sessions to reach stability (third column). Average response rates ( $\mathrm{r} / \mathrm{min}$, fourth column) and average reinforcement rates (sr/min, fifth column) for each subject over the six last sessions of each condition. Ranges are presented in parentheses.

\begin{tabular}{|c|c|c|c|c|}
\hline Pigeon & Conditions & $\begin{array}{l}\text { Sessions } \\
\text { to stability }\end{array}$ & $\mathrm{r} / \mathrm{min}$ & $\mathrm{sr} / \mathrm{min}$ \\
\hline \multirow[t]{3}{*}{553} & Baseline & 43 & $28.02 \quad(22.90-31.97)$ & $1.93(1.95-1.91)$ \\
\hline & Final & 16 & $42.45 \quad(32.29-49.34)$ & $1.95(1.94-1.96)$ \\
\hline & Baseline & 16 & $44.97 \quad(39.38-53.47)$ & $1.95(1.94-1.97)$ \\
\hline \multirow[t]{7}{*}{510} & Baseline & 42 & $84.64(80.81-91.84)$ & $1.97(1.96-1.98)$ \\
\hline & Initial & 13 & $87.94(82.25-101.17)$ & $1.96(1.93-1.98)$ \\
\hline & Baseline & 14 & $78.45(74.41-84.03)$ & $1.97(1.95-1.98)$ \\
\hline & Final & 35 & $65.06(50.18-78.36)$ & $1.97(1.95-1.98)$ \\
\hline & Baseline & 86 & $62.28(51.66-73.05)$ & $1.98(1.98-1.99)$ \\
\hline & Random & 69 & $57.89(52.47-63.77)$ & $1.92(1.70-1.98)$ \\
\hline & Baseline & 17 & $68.94(60.56-72.85)$ & $1.99(1.98-1.99)$ \\
\hline \multirow[t]{5}{*}{778} & Baseline & 52 & $69.27(62.63-76.46)$ & $1.97(1.95-1.99)$ \\
\hline & Random & 15 & $58.41(50.04-65.37)$ & $1.95(1.92-1.97)$ \\
\hline & Baseline & 14 & $71.26(65.23-76.29)$ & $1.99(1.98-1.99)$ \\
\hline & Initial & 32 & $62.61(54.76-70.34)$ & $1.97(1.95-1.98)$ \\
\hline & Baseline & 26 & $72.90(67.78-84.22)$ & $1.97(1.95-1.98)$ \\
\hline
\end{tabular}




\begin{tabular}{|c|c|c|c|}
\hline Final & 55 & $56.10(52-28-63.14)$ & $1.98(1.96-1.99)$ \\
\hline Baseline & 27 & $77.07(71.37-81.58)$ & $1.98(1.93-1.99)$ \\
\hline Baseline & 40 & $87.21(79.86-93.61)$ & $1.80(1.62-1.98)$ \\
\hline Initial & 13 & $57.25(47.25-71.96)$ & $1.41(1.22-1.74)$ \\
\hline Baseline & 14 & $97.78(90.42-105.16)$ & $1.83(1.60-1.99)$ \\
\hline Random & 21 & $66.00(16.46-97.43)$ & $1.63(1.21-1.89)$ \\
\hline Baseline & 35 & $71.79(68.59-75.27)$ & $1.91(1.85-1.99)$ \\
\hline Final & 58 & $31.64(27.02-33.34)$ & $1.86(1.83-1.93)$ \\
\hline Baseline & 85 & $28.15(20.65-35.09)$ & $1.83(1.70-1.90)$ \\
\hline
\end{tabular}



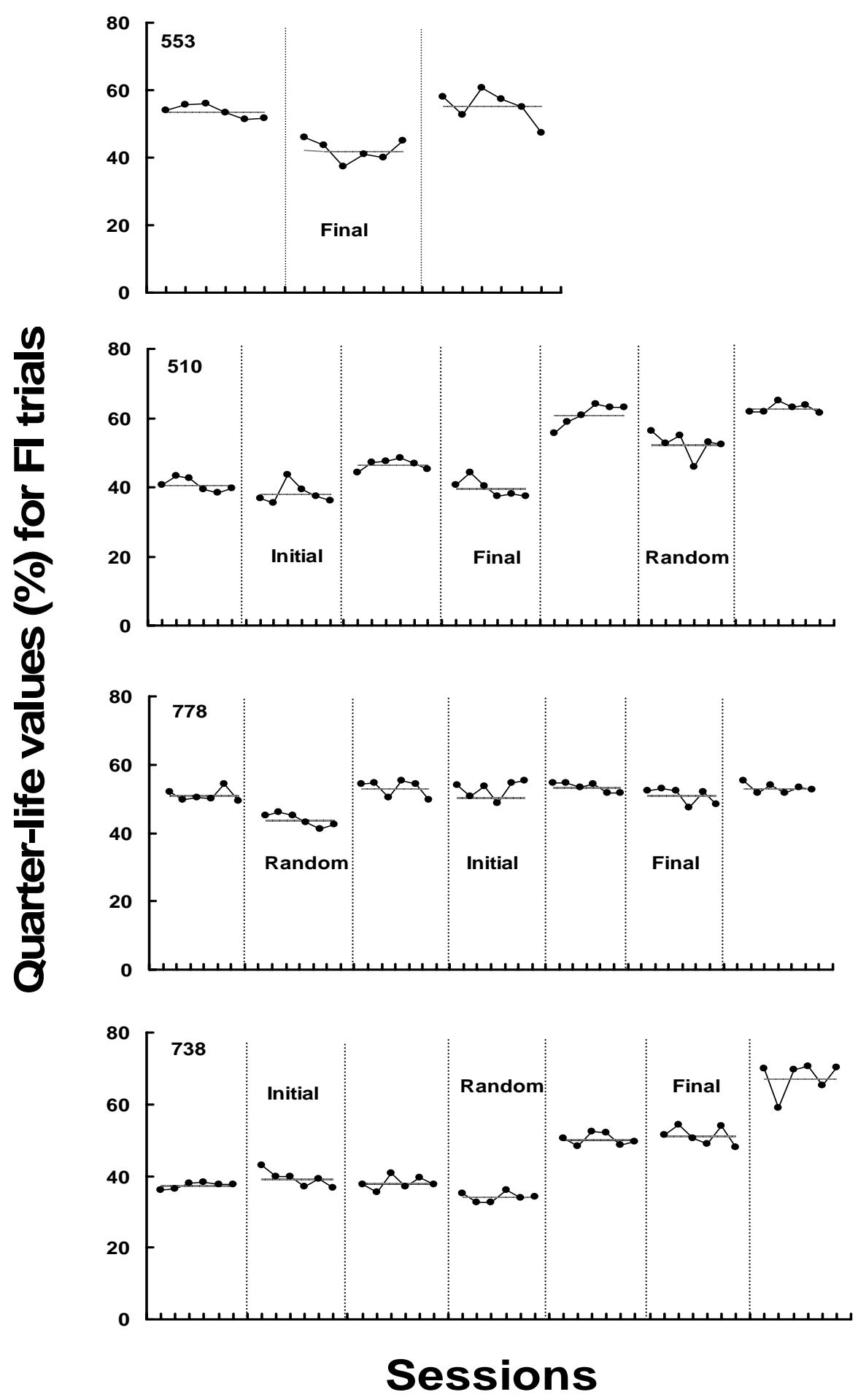

Figure 4. Quarter-life (QL) values for all FI trials across sessions for each subject. Filled circles represent QL values per session. Horizontal lines within each condition are averages of corresponding last six sessions. Disruption conditions are labeled accordingly and baseline conditions are unlabeled. 
was corrected. Due to a lowered response rate during the last condition (Final), Pigeon 738 received remedial training. This training consisted of five days in which a simple FI 5-s schedule was progressively increased until FI 30 s. Nonetheless, even after such remedial training, response rates remained low for Pigeon 738.

Quarter-life values for disrupted and nondisrupted FI trials were calculated separately for each session during each disruption condition and are shown in Figure 5. For these QL values, two types of FI trials were separately analyzed within each session of the disruption condition: disrupted FI trials (i.e., those trials in which response-independent food was delivered) and nondisrupted FI trials. A QL was calculated separately for each of these two types of FI trials. The differences in the QL values during disrupted and nondisrupted FI trials was either small or nonexistent during the Initial condition, although for Pigeon 510 a slight decrease was observed for the QL values for the disrupted FI trial relative to the QL values for the nondisrupted FI trials. For the Random condition, increased variability was observed. The Final condition produced the most marked changes from baseline for Pigeons 553, 510 and 738, specifically, decreased QL values for the disrupted FI trials relative to the QL values during the nondisrupted FI trials. These differences occurred early for Pigeon 553, and immediately after the condition changed for Pigeon 738. For Pigeon 510, the change occurred in a gradual fashion. Specifically, after five sessions of the Final condition, the QL values for the disrupted FI trials became different from the QL values for the nondisrupted FI trials.

The QL values for disrupted and nondisrupted FI trials were less distinct from each other for Pigeon 778. After the first five sessions of the Final condition, the QL values for the disrupted and nondisrupted FI trials separated, with the QL values for the disrupted FI trials being of lower value than the QL values for the nondisrupted FI trials. During the sixth session, 


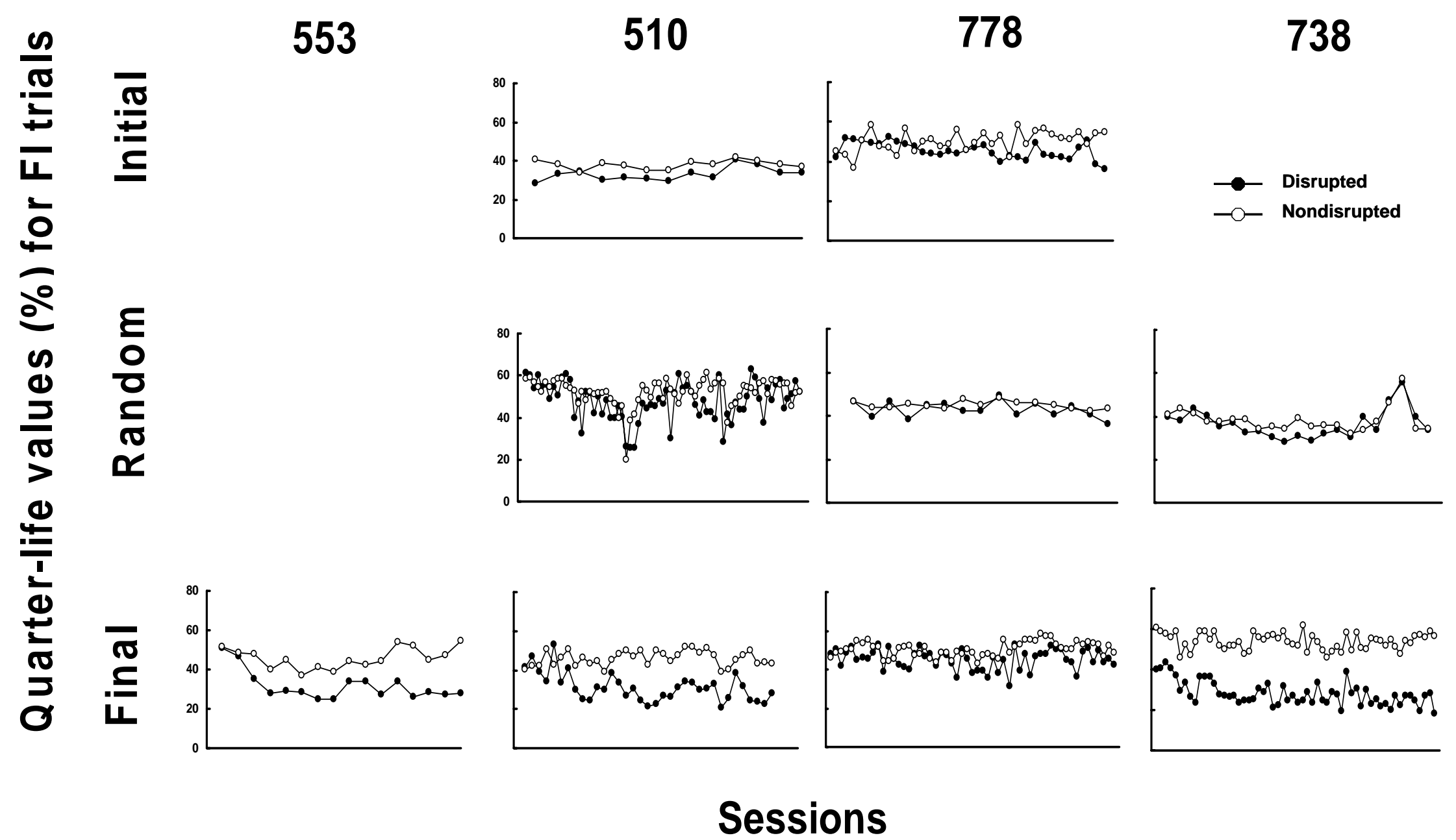

Figure 5. Quarter-life values (QL) for disrupted (filled circles) and nondisrupted (unfilled circles) FI trials across all sessions for each disruption condition (Initial, Random, Final) for each subject. Disruption conditions are shown in rows and subjects (553, 510, 778, \& 738) in columns. 
the two QL values were approximately the same. Similar cycles continued to occur throughout the entire condition.

To confirm that changes occurred during the Initial condition, three QL values were calculated for all the sessions of this condition: the first for the disrupted FI trial, the second for the next FI trial, and the third for the nondisrupted FI trials. These three QL values for all subjects exposed to the Initial condition are compared in Figure 6. For Pigeon 510 the QL for the FI trial immediately following the disrupted FI was of slightly higher than were the QL values for the disrupted FI trials from Session 4 through 10. For Pigeon 778 the QL values for the FI trial immediately following the disrupted FI trial were highly variable. Still, for both Pigeons 510 and 778, the QL for nondisrupted FI trials yielded higher values than the QL values for the disrupted FI trials.

The QL values for the peak trials are shown in Figure 7. Recall that the peak trial was 90 s and stability was defined in part by the QL values for the first third of the trial. Quarter life values for the second third of the peak trial also are shown, however, to provide a more complete description of responding during that part of the procedure. The first third represents the first 30 s of the trial, and QL values were more disrupted here by disruption of the immediately preceding FI trials than were the second third, which corresponds to the second $30 \mathrm{~s}$ of the trial. Three degrees of disruption were identified, as reflected by the QL values for the first third of the peak trial. Specifically, the Final condition produced the highest level of disruption, by decreasing the QL values when compared to previous baseline level. The Initial condition produced no disruption when compared to corresponding baseline QL values. The Random condition decreased the QL values from the previous baseline levels of QL values to 


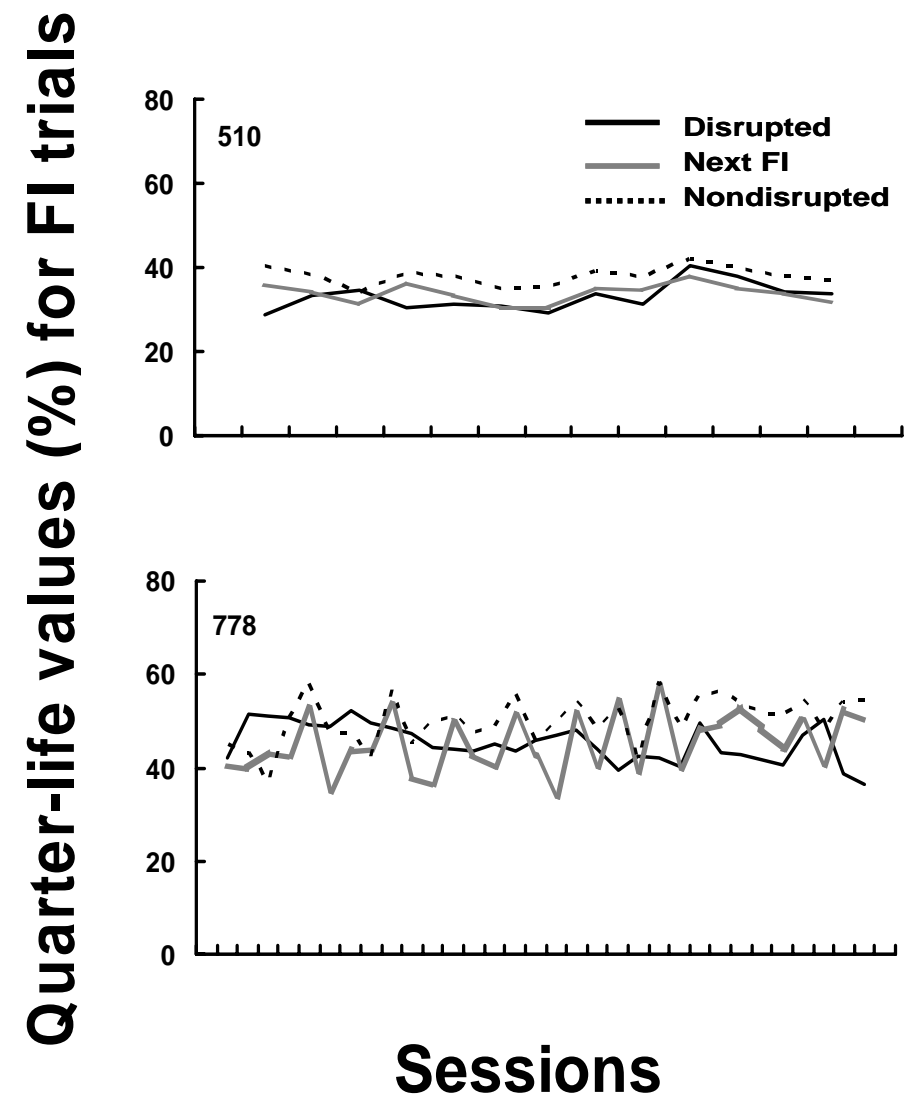

Figure 6. Quarter-life (QL) values for the disrupted, next and nondisrupted FI trials of the Initial condition for each subject. The solid line represents QL values for the disrupted FI trial, the gray line represents QL values for the next FI trial, and the dashed line represents QL values for the nondisrupted FI trials 

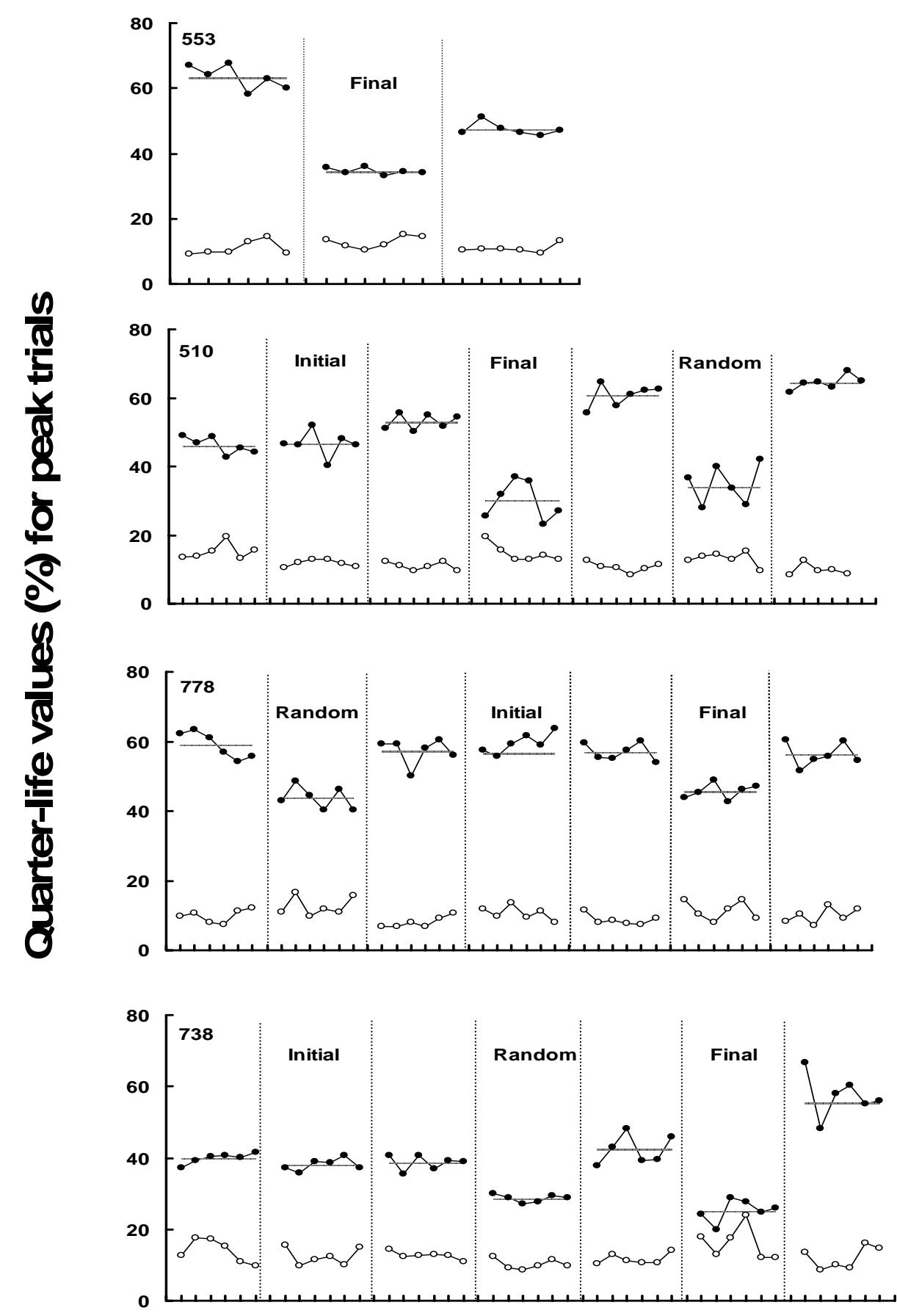

Sessions

Figure 7. Quarter-life (QL) values for the first third (filled circles) and second third (unfilled circles) of the peak trial across sessions per subject. Data for the last six sessions of each condition are shown. Horizontal lines represent average QL values for the first third of the peak trial within each condition. Disruption conditions are labeled accordingly and baseline conditions are unlabeled. 
intermediate values, between those produced by the Final and the Initial conditions. The QL values for the second third of the peak trial were only affected by the Final condition for Pigeons 510, 778, and 738: specifically, these values increased. In addition to the changes in QL values for the first third of the trial in the Final condition, both QL values tend to converge during this condition. Inspection of individual trials suggested that QL values were representative summary measures. This trial-by-trial inspection was performed intermittently for FI and peak trials across all experimental conditions.

The peak times for the last six sessions of each condition are shown in Figure 8. Overall peak times were highly variable across conditions. The most obvious change was a decrease from baseline, when the Final condition was in effect. The Random condition increased the variability of the peak times, and the Initial condition did not change peak times systematically from the baseline conditions.

Peak rates, measured in responses per second (resp/s) are shown in Figure 9. In general, for all pigeons, peak rates decreased during the three disruption conditions and recovered during baseline reversals.

Delay of disruption gradients are orderly functions that result from the calculation of the percent change from baseline for each of the three types of disruption: Initial, Random and Final. Each percentage was based on the last six sessions of corresponding baseline and the specific disruption condition. They were named delay of disruption gradients because each condition involved a different temporal location or delay for a disrupter to occur. The name also involves a relation with delay of reinforcement gradients that will be later discussed.

These gradients were based on three measures of the peak trial and are shown in Figure 10. Gradients based on QL values for the first third of the peak trial are shown in the first row, 

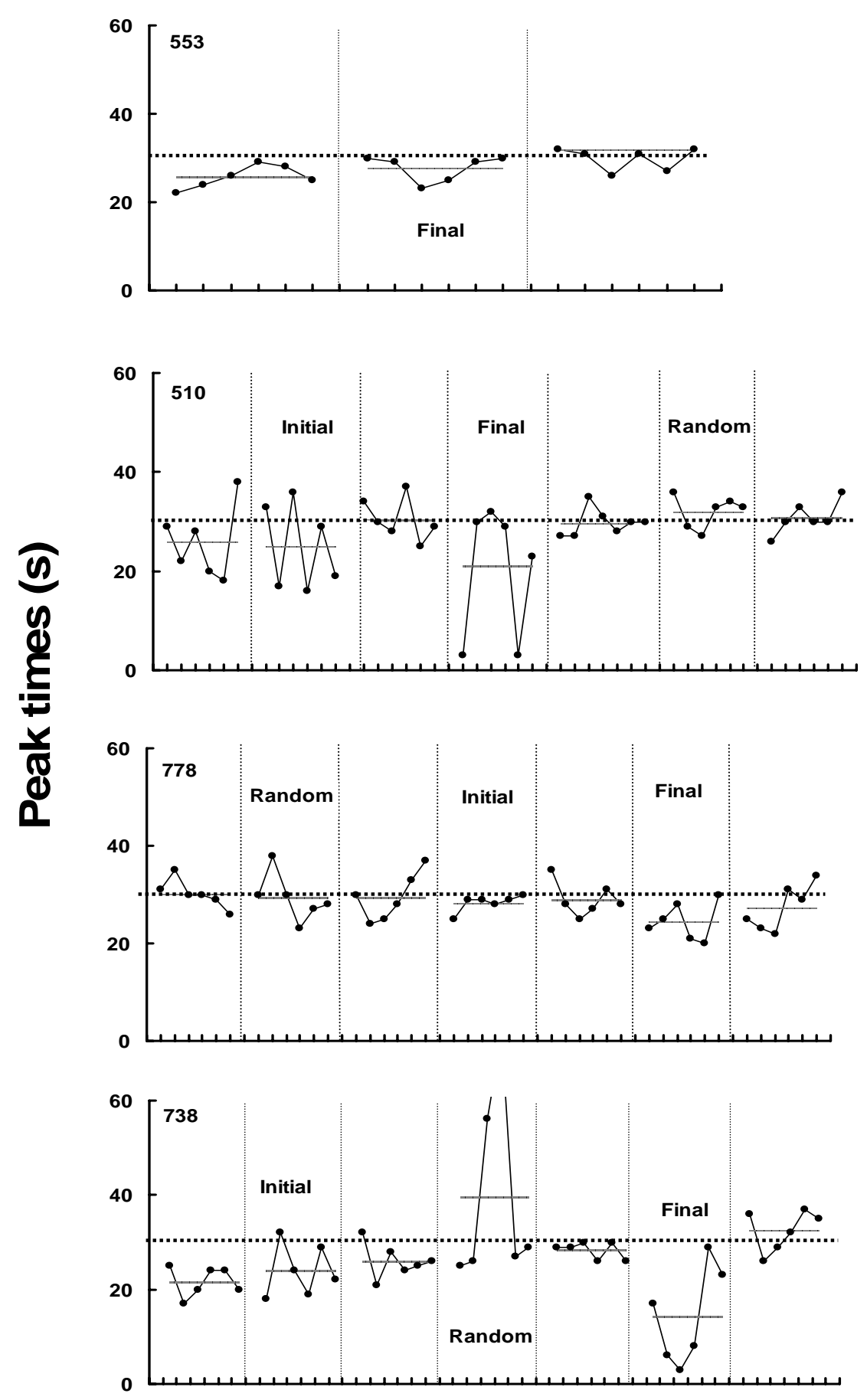

Sessions

Figure 8. Peak times (s) for the last six sessions of each condition for each subject. The solid line represents peak times. Horizontal lines within each condition represent the average peak time of the last six sessions per condition. Horizontal solid lines represent the expected peak time for the baseline condition (30 s). Disruption conditions are labeled accordingly and baseline conditions are unlabeled. 

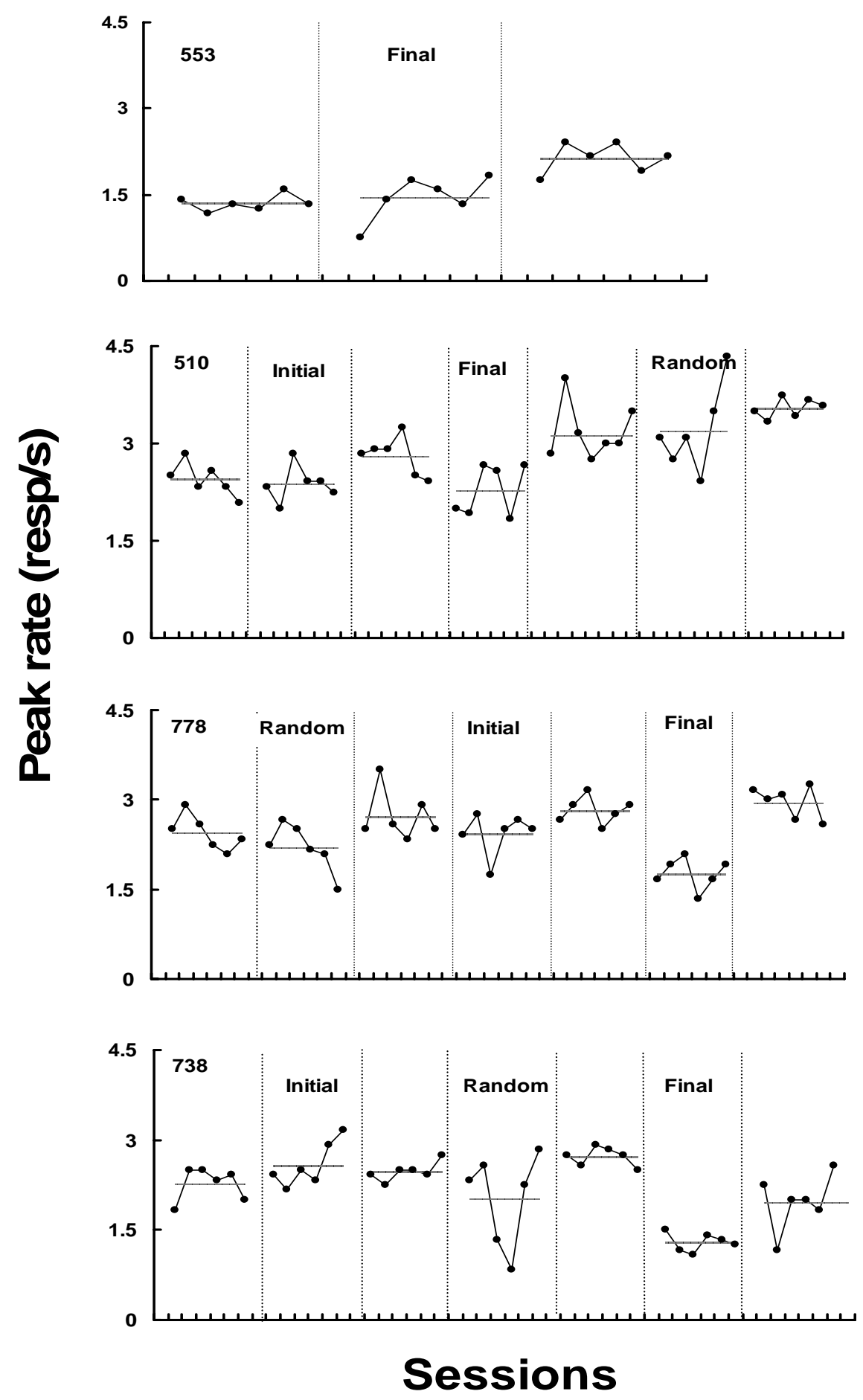

Figure 9. Peak rates (resp/s) for the last six sessions of each condition for each subject. Horizontal lines within each condition represents the average peak time of the last six sessions per condition. Horizontal dashed line represents the expected peak time for the baseline condition (30 s). Disruption conditions are labeled accordingly and baseline conditions are unlabeled. 


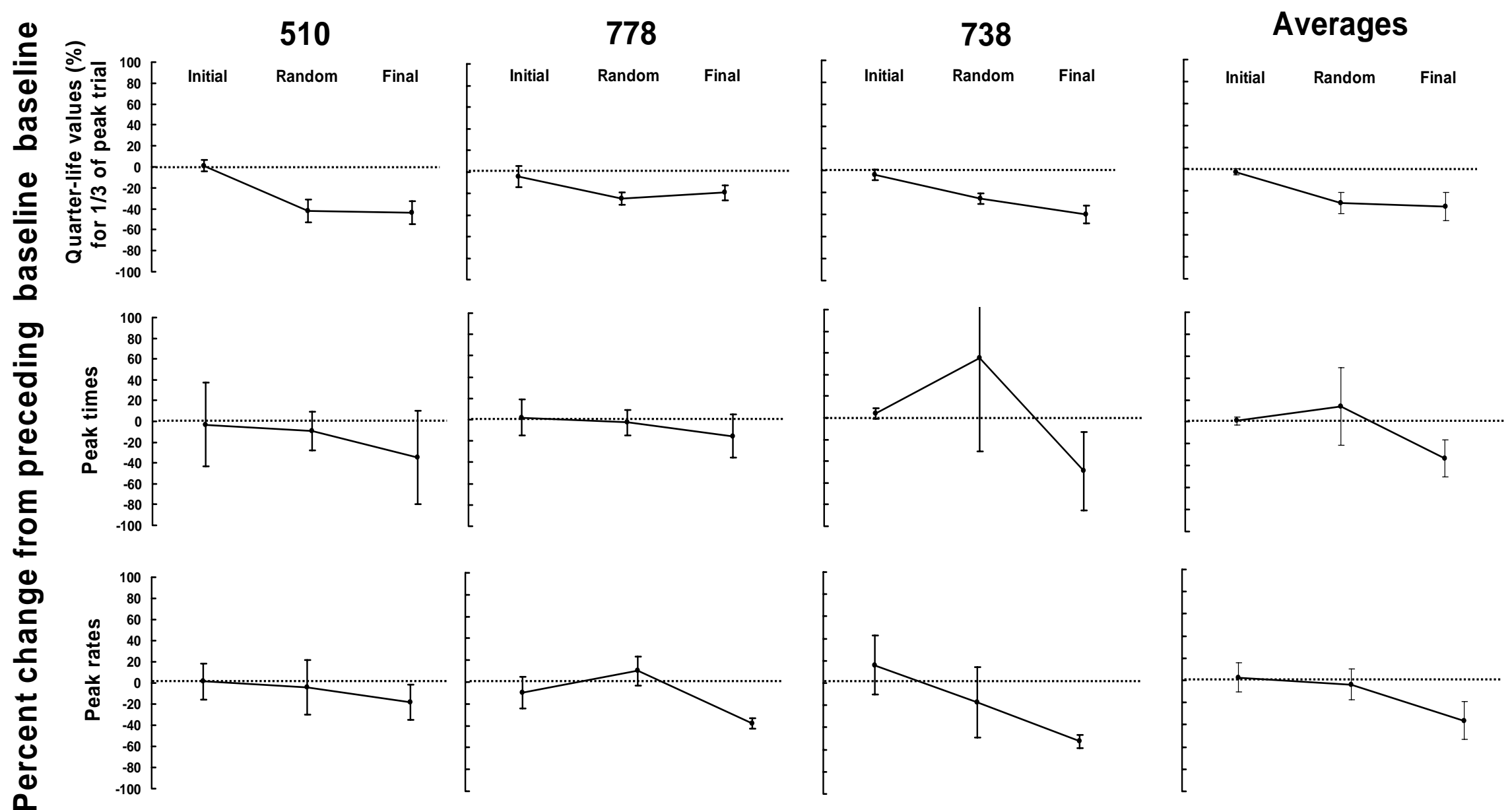

Figure 10. Delay of disruption gradients for each pigeon (columns) based on QL values for the first third of the peak trials (first row), peak times (second row), and peak rates (third row). Each data point is an average of the last six sessions of each condition and bars that extend from each data point represent standard deviations. Averages and standard deviations for each measure, between pigeons are presented on the fourth column. Degrees of disruption are shown by the percent change from previous baseline (y-axis) for each disruption condition (x-axis). Dashed line within each figure represents baseline level for each measure. 
gradients based on the peak times in the second row, and gradients based on peak rates are shown in the third row of Figure 10. The gradients were calculated based on the average of the last six sessions. Variability also was assessed by the calculation of standard deviations for each set of six values. The gradients based on the QL values for the first third of the peak trial were consistent with the disruptions described previously in Figure 7. The Initial condition did not differ from corresponding baseline levels. The Random condition produced a slight decrease in the QL values for the first third of the peak trial. The Final condition disrupted these QL values the most relative to the corresponding baseline QL values.

The gradients for the peak time reveal a similar pattern to those of the gradients based on the QL values for the first third of the peak trial. A noticeable difference, however, was observed for Pigeon 738, in that the peak times during the Random condition were higher than those during the corresponding baseline. These results were due to higher levels of variability for the peak times $(\mathrm{SD}=20.60)$, as compared to the variability for the QL values for the first third of the peak trials $(\mathrm{SD}=1.06)$ shown in Table 2 . This table contains the standard deviations for the last six sessions of each condition, for all pigeons, based on QL values, peak times and peak rates.

Delay of disruption gradients based on peak rates also reveal pattern similar to the previously described gradients. The highest degree of disruption for peak rates was produced by the Final condition.

Finally, to explore the acquisition of temporal control during the first baseline condition, the number of FI trials (2, 3, 4, \& 5) was correlated with the QL values obtained for each of those FI numbers in a sequence of the first baseline sessions. To calculate these QL values, the FI trials were classified within each session according to the number of FI trials preceding the peak trial $(2,3,4$, and 5). A QL was calculated for each of these groups of FI trials, so four QL 
Table 2

Averages and standard deviations (in parentheses) for all pigeons, for each condition, based on $Q L$ values for FI trials, $Q L$ values for the first third of the peak trial, peak times, and peak rates. Data are from the last six sessions of each condition.

Pigeon Conditions QL FI trials QL peak trials Peak times (s) Peak rates (resp/s)

\begin{tabular}{|c|c|c|c|c|c|}
\hline \multirow[t]{3}{*}{553} & Baseline & $53.61(1.94)$ & 63.38 (3.69) & $25.67(2.58)$ & $1.35(1.72)$ \\
\hline & Final & $42.16(3.32)$ & 34.60 (1.06) & 27.67 (2.94) & $1.44(4.68)$ \\
\hline & Baseline & $55.20(4.80)$ & $47.44(1.93)$ & $32.00(2.64)$ & $2.14(3.20)$ \\
\hline \multirow[t]{7}{*}{510} & Baseline & $40.60(1.90)$ & $46.13(2.47)$ & 25.83 (7.39) & $2.44(0.26)$ \\
\hline & Initial & 38.07 (2.98) & 46.57 (3.77) & $25.00(8.74)$ & $2.38(0.27)$ \\
\hline & Baseline & $46.59(1.54)$ & $53.07(2.25)$ & $30.50(4.32)$ & $2.81(0.31)$ \\
\hline & Final & 39.66 (2.68) & $30.02(5.66)$ & $21.14(13.51)$ & $2.28(0.40)$ \\
\hline & Baseline & $60.88(3.21)$ & $60.66(3.35)$ & $29.67(3.08)$ & $3.13(0.45)$ \\
\hline & Random & 52.49 (3.54) & $34.13(5.70)$ & 32.00 (3.35) & $3.19(0.67)$ \\
\hline & Baseline & 62.85 (1.39) & $64.46(2.09)$ & $30.83(3.37)$ & $3.54(0.16)$ \\
\hline \multirow[t]{6}{*}{778} & Baseline & $50.94(1.85)$ & $58.91(3.78)$ & 30.17 (2.93) & $2.44(0.29)$ \\
\hline & Random & 43.82 (1.80) & 43.81 (3.26) & 29.33 (4.97) & $2.19(0.40)$ \\
\hline & Baseline & $53.14(2.40)$ & $57.17(3.77)$ & $29.50(4.93)$ & $2.72(0.43)$ \\
\hline & Initial & $50.46(2.63)$ & $56.68(2.79)$ & 28.33 (1.75) & $2.43(0.36)$ \\
\hline & Baseline & $53.45(1.39)$ & $56.88(2.57)$ & $29.00(3.52)$ & $2.82(0.23)$ \\
\hline & Final & $50.92(2.43)$ & 45.67 (2.29) & 24.50 (3.94) & $1.76(0.27)$ \\
\hline
\end{tabular}




\begin{tabular}{|c|c|c|c|c|c|}
\hline & Baseline & $51.46(2.08)$ & $56.33(2.14)$ & $27.33(4.76)$ & $2.96(0.28)$ \\
\hline \multirow[t]{7}{*}{738} & Baseline & $37.30(0.98)$ & $39.84(1.52)$ & $21.67(3.14)$ & $2.26(0.28)$ \\
\hline & Initial & 39.21 (2.32) & $38.13(1.74)$ & $24.00(5.55)$ & $2.58(0.38)$ \\
\hline & Baseline & 37.97 (1.89) & 38.69 (2.09) & $26.00(3.74)$ & $2.47(0.16)$ \\
\hline & Random & 34.08 (1.37) & $28.73(1.06)$ & 39.50 (20.59) & $2.03(0.78)$ \\
\hline & Baseline & $50.24(1.72)$ & $42.37(4.16)$ & $28.33(1.86)$ & $2.72(0.16)$ \\
\hline & Final & $51.21(2.64)$ & $25.22(3.14)$ & $14.33(10.35)$ & $1.29(0.16)$ \\
\hline & Baseline & $67.50(4.55)$ & $55.58(6.14)$ & $32.50(4.32)$ & $1.97(0.47)$ \\
\hline
\end{tabular}




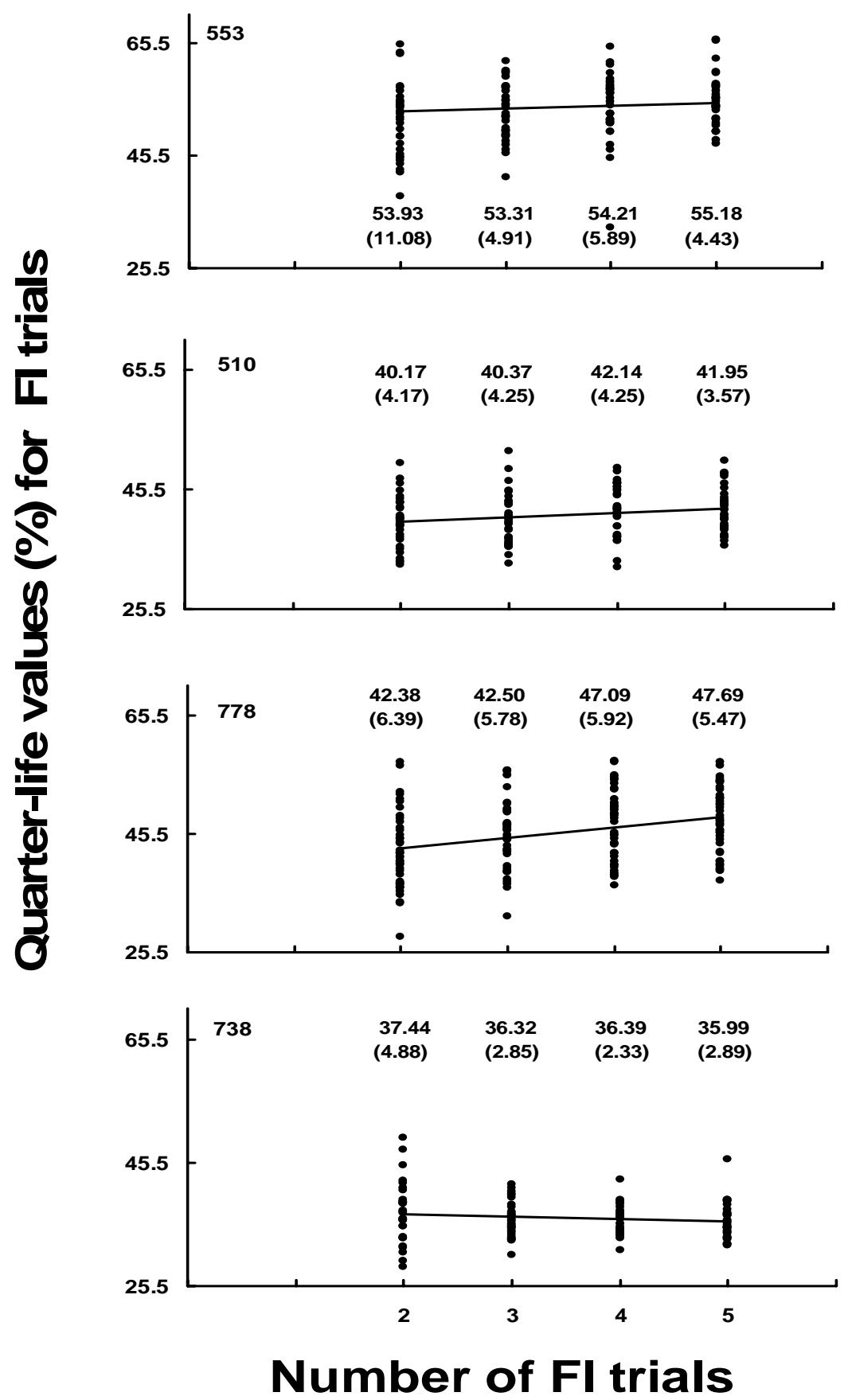

Figure 11. Scatterplots based on the number of FI trials (x-axis) and QL values for FI those specific FI trials (y-axis). Filled circles represent all QL values obtained for 2, 3, 4 \& 5 FI trials. Numbers within the figure are averages and numbers in parentheses are standard deviations of the corresponding QL values. Solid lines within each figure are linear trend lines. 
values were calculated per session. Figure 11 shows the scatterplots and linear trend lines for each subject. For Pigeons 553, 510 and 778 the trend line suggests a positive linear relation between the number of FI trials and the QL values (i.e., as the FI number increases so does the QL values). Only for 738, the trend line suggests negative linear relation between the number of FI trials and the QL values. Thus, the number of FI trials might be related to the level of temporal control acquired within the preceding FI trials and ultimately to temporal control in the peak trials.

\section{Discussion}

In general, disruption of the QL values for the first third of the peak trials in the Initial condition produced the lowest, the Final condition the highest, and the Random condition an intermediate and most variable level of disruption. Also, the most noticeable difference between disrupted and nondisrupted FI trials (the disrupted yielded lower QL values than the nondisrupted) was observed during the Final condition. These results demonstrate that the temporal location of disruption, defined here as the delivery of response-independent food, within the FI trials preceding the peak trials in a PIP, is a variable that deserves further attention when studying response patterns developed under temporal control procedures such as the PIP. The systematic effects of this variable, unstudied until now, have implications for both the analysis of temporal control and for the study of resistance to change.

Before placing this research into a broader context, it is useful to consider procedural aspects of the present experiment that may have contributed to the results obtained. Thus, procedural variables are first discussed to account for the results obtained during FI and peak trials. Subsequently, the results obtained in the present research are compared to previous 
findings concerning the relation between temporal control and resistance to change. Finally, the theoretical contributions of the concept of a delay of disruption gradient are elaborated.

\section{Procedural Variables}

To begin the discussion of procedural variables that might contribute to the results obtained in the present experiment, recall that one of the main purposes of the PIP is to test and examine a more extended pattern of responding than the one obtained in the FI schedules that precede it. As Grace and Nevin (2000) have mentioned, the peak trials allow for the analysis of the increasing and decreasing rates of responding that form the characteristic pattern of a normallike curve (Meck, 2003). In the PIP, there is a procedural distinction, detectable by the experimenter, between FI and peak trials. At the same time, however, from the perspective of the pigeon, these two parts of the procedure should be indistinguishable. The next two sections address the results obtained for these parts of the PIP produced by the delivery of free food. Procedural aspects will be discussed to examine whether the results obtained indicated discrimination of the onset of the peak trials when disruption conditions were in effect.

Results obtained during FI trials. For the Initial condition, the disrupted FI trials yielded slightly lower QL values than QL values for nondisrupted FI trials (see the first row of Figure 5). These effects, though, were only observed in two out of four pigeons for reasons previously stated in the Results section. In the Initial condition, even though the first FI trial was disrupted, it was followed by other opportunities to earn a reinforcer (1, 2, 3, or 4 FI trials). Thus, there was an opportunity for FI patterns to recover.

In the Final condition, QL values for disrupted FI trials were substantially lower than QL values for nondisrupted FI trials for three out of four pigeons $(553,510,738$ but not for 778$)$. The effects of the disrupter in the last FI (Final condition) were more disruptive than the effects 
of the disrupter delivered during the first FI trial (Initial condition). This was due to the proximity of the disrupter in the last FI trial to the peak trial during the Final condition, that is, there was no chance for FI responding to recover to its typical pattern following disruption.

For the Random condition, there was increased variability in both QL values for disrupted and nondisrupted FI trials or no difference between QL values for disrupted and nondisrupted FI trials. These results might be due to an averaging effect of the effects of some disrupters that occurred during the first, the last, or the intermediate FI trials. The fact that the location of the disrupted FI trial was not constant as in the Initial and Final conditions could be related to the overlapping QL values for disrupted and nondisrupted FI trials shown in the second row of Figure 5.

Results obtained during peak trials. The results obtained in the Initial condition for the peak trials, namely the QL values for the first third of the peak trials, peak times and peak rates, were likely due to the opportunity to recover characteristic FI schedule control before the onset of the peak trial. Quarter-life values for the peak trials, especially those calculated for the first third of the trial, along with peak times and some cases of the peak rates, were most changed during the Final condition.

In the Initial condition, for Pigeons 510 and 778, the QL values for the disrupted FI trial initially decreased relative to baseline (see first row of Figure 5) then, the mean QL values for the next FI trial slightly increased relative to the QL values for the disrupted FI trial (see Figure 6). Finally, the mean $\mathrm{QL}$ values for the first third of the peak trial were higher than the two previously described (see Figure 7). This progression in the QL values within a sequence is evidence of the recovery of positively accelerated response patterns from the disruption within the first FI trial. 
In the Final condition, the disrupted FI trials and the first third of the peak trials were disrupted at similar levels. That is, the mean QL values for the disrupted FI trials and for the first third of the peak trials were similar (see Figures 5 and 7). This could be related to a potential discrimination of the onset of peak trials in the Final condition. In sum, in both the Initial and Final conditions, disruption within the FI trial carried over to the next trial (i.e., to the next FI trial in the Initial condition and to the first third of the peak trial in the Final condition). The Final condition, though, produced greater disruption of both disrupted FI and peak trial than that observed when the Initial condition was studied.

Findings such as those just described could be related to the fact that disrupters during the last FI trial could have acquired discriminative properties (Lattal \& Abreu-Rodrigues, 1997) due to their proximity to the peak trial. If the onset of a peak (extinction) trial were thus signaled by the disrupters in the last FI trial, then this might in part account for the disruption because the peak trial would become a discriminated period of extinction. Thus, the temporal location of the disrupter becomes another variable to consider when examining resistance of behavior to change, similar to those variables suggested by Nevin, such as prefeeding or rate of response-independent food delivery.

As during the FI trials, the intermediate disruption produced by the Random condition could be described as an averaging effect of disrupters occurring during the first and last FI trials. Still, it remains unclear why there were cases in which the disruption produced by the Random condition either increased variability of the QL values, peak times and peak rates, or was similar to that in the Final condition for Pigeon 778 (which also showed the least degree of disruption in the Final condition). 
To decrease the probability of discrimination of the onset of the peak trial, the stimulus conditions (houselight and keylight on) were maintained constant and the number of FI trials was variable. If, however, the pigeons did discriminate the onset of the peak trial, then responding during the peak trials (where extinction was in effect) could be considered more susceptible to disruption than responding maintained by FI trials. Following the suggestions of Nevin and colleagues, the presence of reinforcement during the FI trials would result in behavior that is more resistant to change than behavior maintained during peak trials, where reinforcement was not presented. If that were the case, then, in general, QL values for the peak trials would have been expected to decrease when the preceding FI performance was disrupted. This, however, did not occur during all disruption conditions, suggesting that the peak trial was not discriminated, at least during baseline conditions.

The baseline structure against which the changes in peak trial performance were assessed also should be considered in a discussion of the peak trial results. In general, in baseline conditions, the results were related to the number of FI trials preceding the peak trial. Because the FI trials prior to the peak trial represent a training phase for the peak trial, the number of FI trials could have differentially affected the development of temporal control during that part of the PIP. For three $(553,510, \& 778)$ out of four pigeons, as the number of preceding FI trials increased, the overall QL values for those FI trials also were higher (see Figure 11). This positive relation might have some bearing on the development of temporal control on the peak trial. It could be that if more than 2, 3, 4 or 5 FI trials (as in the present experiment) had preceded the peak trial, then higher QL values might have been obtained for the peak trials in baseline conditions. This, in turn, might have changed the effects of the disruption conditions relative to the ones obtained in the present experiment. Other procedural variables such as the 
characteristics of the delivery of the disrupter, the number of sessions each condition was in effect, and the examination of steady states instead of transitions might also have contributed to the results.

Delivery of the disrupter. The houselight and keylight were on while the disrupter (the response-independent food delivery) was in effect, a procedural difference from other studies in which these two stimuli are not present (turned off; as in Lattal and Bryan, 1976; or because the food was delivered during a blackout period as in Grace and Nevin, 2000). The rationale for keeping these lights on was so that the disrupter would be more or less independently superimposed on the FI trials. By doing so, the same stimuli associated with FI reinforcement would not be associated with the response-independent food. Lattal and Bryan found that disrupters decreased QL values, relative to baseline, down to $25 \%$. The present findings are more complex because of the schedule dynamics resulting from the variable location of a single disrupter within an FI sequence. These procedural differences between Lattal and Bryan and the present experiment raise the following empirical question. Is there a difference between presenting the disrupter with the same stimuli as the reinforcer as opposed to presenting it with different stimuli? To confirm the dissociation between reinforcer and disrupter, both stimulus conditions, keylight and houselight on versus off during disrupter delivery might be compared experimentally.

Number of sessions that each condition was in effect .The number of sessions that each condition was in effect depended directly on meeting the stability criteria. Frequently, the number of sessions required to meet stability increased as the experiment progressed. This finding is related to the fact that the return to baseline after each disruption condition did not result in response recovery that was exactly like previous baseline performance. Such partial 
recovery could mean that the effects of the previous disruption were carried forth and thereby affected subsequent manipulations in a cumulative fashion. Thus, each experimental phase might well be considered a new context for temporal control influenced by the history consisting of previous manipulations. Also, the fact that the number of sessions required to meet the stability criteria increased as the experiment progressed could suggest that the behavior was becoming more resistant to change. As a consequence of the increasing exposure to the disruption conditions, the temporally controlled behavior required more sessions to be disrupted and also to recover.

Steady states versus transitions. Conclusions drawn from the present data concerning disruption effects were based on steady-state performance. The disruption effects observed during the Final condition (decreased QL values for FI trials and peak trials, decreases on peak rates, and increased in variability of peak times) were consistent with the findings of Grace and Nevin (2000). These authors evaluated the effect of disruption based on the first five sessions of the resistance-to-change phase in the experiment, that is, during transitional periods rather than the present analyses of steady-state performance. Grace and Nevin's findings might suggest that the effects of the specific kind of disruption on temporally controlled responding were transitional. The present research, however, adds generality to the study of disruption of temporal control because by examining steady-states of responding, the disruption effects were in fact shown to be sustained over multiple sessions and not merely transitional. Specifically, the effects produced by the Random and Final conditions persisted, and in some cases changed, for far longer than the five sessions reported by Grace and Nevin.

Temporal Control and Resistance to Change 
The concept of resistance to change is largely based on the analysis of responding maintained on multiple schedules (Grace \& Nevin, 2000). Most often, richer schedules are more resistant to change than are leaner ones (e.g., Nevin, 1974). The present results extend the concept of response strength to a temporal control procedure, specifically to the study of resistance of temporally controlled behavior to change. Introducing a disrupter into a stable baseline of temporally controlled behavior and assessing the effects of such a disrupter relative to baseline responding follows the logic and analysis employed in earlier experiments where resistance of simple operant responding to change has been studied. This approach also has been taken in several previous studies of temporally controlled behavior (c.f., Aum et al., 2004; Buhusi, 2003; Meck \& Church, 1987; Grace and Nevin, 2000; Lieving, 2003; Meck, 1996; Odum \& Schaal 2000).

From the studies mentioned in the previous paragraph, the one most similar to the present experiment is Grace and Nevin's (2000). These authors examined the disruption of temporal control only during peak trials and not FI trials because, as mentioned earlier in this discussion, peak trials allow for the study of more extended patterns of responding than FI schedules (because they remain in effect far longer than a standard FI trial). Grace and Nevin reported rightward shifts of the peak times and decreased peak rates when response-independent food was delivered during the blackout of a multiple PIP. This decrease in temporal control was evidenced by the change of the response distributions from the peak trial relative to baseline to a negatively skewed distribution. These findings can be interpreted as underestimations of time produced by disruption.

Similar to the results of Grace and Nevin (2000), peak rates decreased relative to baseline peak rates during the Final and Random conditions. This finding was consistent with the fact that 
in the present experiment, overall rates of responding decreased relative to baseline in all the disruption conditions (see fourth column in Table 1). Contrary to the results obtained by Grace and Nevin, the peak times in this experiment decreased during the Final condition. This finding along with decreased QL values for the first third of the peak trial in the Final condition indicated that response distributions for the peak trials were shifted to the left relative to baseline distributions. These results can be interpreted as an overestimation of temporal intervals in the Final disruption. The Random condition caused increased variability of the peak times, not a consistent shift of the response distributions.

The proximity between the disrupter and the peak trial was suggested above to be relevant in accounting for several aspects of the results. If this proximity was related to the disrupter in this final FI trial functioning as a discriminative stimulus correlated with a forthcoming nonreinforcement (extinction) period, then, an effect similar to an extinction burst might have occurred at the beginning of the peak trials in the Final condition. This extinction burst is consistent with the increased response rate at the beginning of the trial indicated by the decreased QL values for the first third of the peak trial and the decreased values of the peak times. If extinction was taking place at the onset of the peak trial, though, then responding would have eventually extinguished throughout the trial, and that did not occur.

Several predictions concerning the effects of resistance-to-change tests by the behavioral theory of timing (BeT; Killeen \& Fetterman, 1988) may be useful in accounting for overestimation of time during peak trials in the present research. In BeT, the speed of the pacemaker is proportional to the rate of reinforcement. The delivery of response-independent food increases the overall access to food relative to the access provided in baseline (Lieving, 2003). Response-independent food is an increase in reinforcement rate, which should, according 
to BeT, increase the speed of the pacemaker (Grace \& Nevin, 2000). Overestimation of time therefore is consistent with predictions of the effects of response-independent food delivery on temporal control. More specifically, according to BeT, because the pacemaker is speeded up, response distributions shift to the left, with resultant decreases in peak times.

The BeT also predicts an underestimation of time in extinction due to lowered speed of the pacemaker. The peak trials are periods of extinction, so based on the results obtained during peak trials, the BeT's prediction concerning extinction was not confirmed. It could be argued, however, that the peak trials are periods where there are reductions of reinforcement and not complete discontinuations of reinforcement, in contrast to the extinction periods used in resistance-to-change tests and which also enter into temporal control effects in BeT. In the present study, each sequence ends with a peak trial but, subsequently (after a 90-s ISI) further opportunities to earn reinforcers (FI trials) follow.

Another procedural difference relevant to the overestimation of time observed during the peak trial in the present experiment was that trials in the present experiment were always compressed within a sequence as opposed to being interspersed by ITIs as in Grace and Nevin's (2000) experiment. If the definition of peak trials as periods of extinction is maintained, and according to BeT the speed of the pacemaker was expected to decrease, it could be argued that the overestimation effects obtained during the last FI trial carried over to the extinction period, because there was no chance for recovery, and so peak times were decreased.

Overestimation of time also was found in some instances by Lieving (2003) when she delivered response-independent food during the blackouts of a multiple FOPP. Lieving noted that both the FOPP and the PIP are used to measure temporal control. Thus, the measure of temporal control obtained by data gathered in a FOPP, the ET50, would be an analogous index of 
temporal control to the peak times and peak rates. Lieving also stated that changes of the ET50 reflect changes of the pacemaker rate and thus changes the reinforcement rate within the experimental sessions, just as the peak times and peak rates. More specifically, in Lieving's experiments, upon delivery of response-independent food according to VT schedules, the ET50 decreased or did not change systematically during the lean components. For the rich components, the ET50 mostly decreased, but sometimes increased relative to baseline levels.

The decreases of ET50 are similar to decreases in QL values and peak times observed in the present experiment. A difference between Lieving's and the present experiment, though, is that she used a VT 5, 10 and $30 \mathrm{~s}$ and found that disruption effects varied as a function of the disrupter magnitude. In the present research, the number of disrupters was constant throughout disruption conditions (one disrupter per sequence for a total of 12 disrupters per session). This frequency of disrupters was lower than the number of disrupters employed by Grace and Nevin (2000). In the latter experiment, disrupters were delivered according to different VT schedules in each 20-s ITI (71 ITIs for a total of 72 trials per session). Thus, the access to food in Grace and Nevin's procedure was considerably higher than in the present experiment. This is yet another procedural aspect that might account for some of the differences between the results obtained by Grace and Nevin and the present experiment.

The rate of disrupters located within FI trials is another variable that could be examined to extend the results of the present experiment. Perhaps a high rate of disrupters might result in satiation within a session. Changes of temporal control within a session due to satiation have been assessed by McSweeney, Roll, and Weatherly (1994). They found that during FI schedules of reinforcement, PRPs and the time to collect a reinforcer increased, and the responses per reinforcer decreased as the session progressed. Satiation in these experiments occurred simply by 
consuming the FI reinforcers. Similarly, disruption produced by satiation (due to increased access to food from programmed reinforcers and disrupters) could be examined in the modified PIP employed in this experiment and assessed through other measures of temporal control such as QL values, peak times and peak rates.

\section{Delay of Disruption Gradients}

The effects on temporal control obtained in this experiment can be conceptualized as a delay of disruption gradient. This conceptualization refers to the relation between the time of disrupter delivery and the onset of the peak trial. Delay of disruption gradients were constructed based on QL values for the first third of the peak trials, peak times, and peak rates.

A consideration in assessing the present gradients shown in Figure 10 is that the Random condition does not correspond with values exactly between Initial and Final. There was no condition in the present experiment where disrupters were delivered in the middle FI trial of a sequence. Instead, the Random condition consisted of some deliveries during the first and last FI trials, and others during intermediate FI trials. One alternative to these mixed locations of the disrupters would be to only analyze only those FI and peak trials disrupted by responseindependent food delivered during intermediate FI trials. The downside of this alternative is that still, potential interactions between the effects of the different disrupter locations, make the results of the Random condition difficult to compare directly to those obtained during the Initial and Final conditions, where the FI location was constant.

As previously stated, some disrupters during the Random condition were delivered during intermediate FI trials. This, added to the viability of an averaging effect resulting from disrupters that occurred during the first and the last FI trials during the Random condition, makes delay of 
disruption gradients a valid analysis to examine and organize the levels of disruption as a function of temporal contiguity of disruption.

Delay of disruption gradients are functionally similar to delay of reinforcement gradients in that increases or decreases in the time between two specific events have systematic effects on responding. More specifically, in delay of reinforcement gradients, the effect of a reinforcer is weakened as the delay between response and reinforcer is increased. In delay of disruption gradients, as the time between disrupter and peak trial increases, the disruption of stabilized temporal control decreases.

Delay of disruption gradients represent a novel and theoretically significant finding because they reveal a relation between temporal control and the important basic learning mechanism of the temporal contiguity between events and their effects on behavior. Temporal contiguity is basic in understanding the development of the flow and shape of response patterns of temporally controlled behavior. When such temporal integrity of stabilized temporal control is disrupted, the organization of response patterns changes, reflecting a decrease in temporal control. 


\section{References}

Abner, R. T., Edwards, T., Douglas, A., \& Brunner, D. (2001). Pharmacology of temporal cognition in two mouse strains. International Journal of Comparative Psychology, 14, 189-210.

Aum S. W., Brown, B. L., \& Hemmes, N. S. (2004). The effects of concurrent task and gap events on peak time in the peak procedure. Behavioural Processes, 65, 43-56.

Baron, A., \& Leinenweber, A. (1995). Effects of a variable-ratio conditioning history on sensitivity to fixed-interval contingencies in rats. Journal of the Experimental Analysis of Behavior, 63, 97-110.

Buhusi, C. V. (2003). Dopaminergic mechanisms of interval timing and attention. In W. H. Meck (Ed.), Functional and neural mechanisms of interval timing (pp. 317-338). Boca Raton, FL: CRC Press.

Catania, C. (1970) Reinforcement schedules and psychophysical judgements. In W. N. Schoenfeld (Ed.), The theory of reinforcement schedules (pp. 15-60). New York: Appleton-Century-Crofts.

Catania, A. C. (1991). Time as a variable in behavior analysis. In I. H. Iversen \& K. A. Lattal (Ed.), Experimental analysis of behavior, Part 1 (pp.1-19). New York: Elsevier Science.

Cheng, K., \& Roberts, W. A. (1991). Three psychophysical principles of timing in pigeons. Learning and Motivation, 22, 112-128.

Drew, M. R., Fairhurst, S., Malapani, C., Horvitz, J. C., \& Balsam, P. (2003). Effects of dopamine antagonists on the timing of two intervals. Pharmacology, Biochemistry, and Behavior, 6875, 1-7. 
Ferguson, S. A., \& Paule, M. G. (1995). Lack of effect of prefeeding on food-reinforced temporal response differentiation and progressive ratio responding. Behavioural Processes, 34, 153-160.

Ferster, C. B., \& Skinner, B. F. (1957). Schedules of reinforcement. New York: AppletonCentury-Crofts.

Freeman, T. J., \& Lattal, K. A. (1992). Stimulus control of behavioral history. Journal of the Experimental Analysis of Behavior, 57, 5-15.

Fry, W., Kelleher, R. T., \& Cook, L. (1960). A mathematical index of performance on fixedinterval schedules of reinforcement. Journal of the Experimental Analysis of Behavior, 3, 193-199.

Gibbon, J. (1977). Scalar expectancy theory and Weber's law in animal timing. Psychological Review, 84, 279-325.

Gollub, L. R. (1964). The relations among measures of performance on fixed-interval schedules. Journal of the Experimental Analysis of Behavior, 7, 337-343.

Grace, R. C., \& Nevin, J. A. (2000). Response strength and temporal control in fixed interval schedules. Animal Learning and Behavior, 28, 313-331.

Hawkes, L., \& Shimp, C. P. (1975). Reinforcement of behavioral patterns: Shaping a scallop. Journal of the Experimental Analysis of Behavior, 23, 3-16.

Herrnstein, R. J. , \& Morse, W. H. (1957). Effects of pentobarbital on intermittently reinforced behavior. Science, 125, 929-931.

Higa, J. (1998). Interval timing: Is there a clock? Behavioural Processes, 44, 87-88.

Higa, J., \& Pierson, D. (1998). Temporal control in rats: Analysis of nonlocalized effects from short interfood intervals. Journal of the Experimental Analysis of Behavior, 70, 35-43. 
Innis, N. K., Mitchell, S. K., \& Staddon, J. E. (1993). Temporal control on interval schedules: What determines the postreinforcement pause? Journal of the Experimental Analysis of Behavior, 60, 293-311.

Killeen, P. R., \& Fetterman, J. G. (1988). A behavioral theory of timing. Psychological Review, 95, 274-295.

Lattal, K. A., \& Abreu-Rodrigues, J. (1997). Response-independent events in the behavior stream. Journal of the Experimental Analysis of Behavior, 68, 375-398.

Lattal, K. A., \& Bryan, A. J. (1976). Effects of concurrent response-independent reinforcement on fixed-interval schedule performance. Journal of the Experimental Analysis of Behavior, 26, 495-504.

Lieving, L. (2003). Temporal control and response strength in a free-operant psychophysical procedure. Unpublished doctoral dissertation, West Virginia University, Morgantown. http://kitkat.wvu.edu:8080/files/3102/Lieving_L_dissertation.pdf.

Malapani, C., \& Rakitin, B. (2003). Interval timing in the dopamine-depleted basal ganglia: From empirical data to timing theory. In W. H. Meck (Ed.), Functional and neural mechanisms of interval timing (pp. 485-514). Boca Raton, FL: CRC Press.

McSweeney, F. K., Roll, J. M., \& Weatherly, J. N. (1994). Within-session changes in responding during several simple schedules. Journal of the Experimental Analysis of Behavior, 62, 109-132.

Meck, W. H. (1996). Neuropharmacology of timing and time perception. Cognitive Brain Research, 3, 227-242.

Meck, W. H. (2003). Introduction: The persistence of time. In W. H. Meck (Ed.), Functional and neural mechanisms of interval timing (pp. xvii-xli). Boca Raton, FL: CRC Press. 
Meck, W. H., \& Church, R. M. (1987). Cholinergic modulation of the content of temporal memory. Behavioral Neuroscience, 101, 457-464.

Miller, M. L., Brodkorb, G. W., \& Branch. M. N. (2001). Tolerance to the effects of cocaine on performance under behavior-correlated reinforcement magnitude. Journal of the Experimental Analysis of Behavior, 76, 217-234.

Nevin, J. A. (1974). Response strength in multiple schedules. Journal of the Experimental Analysis of Behavior, 21, 389-408.

Nevin, J. A. (1988). Behavioral momentum and partial reinforcement effect. Psychological Bulletin, 103, 44-56.

Nevin, J. A., Tota, M. E., Torquato, R. D., \& Shull, R. L. (1990). Alternative reinforcement increases resistance to change: Pavolvian or operant contingencies? Journal of the Experimental Analysis of Behavior, 53, 359-380.

Odum, A. L., Lieving, L. M., \& Schaal, D. W. (2002). Effects of d-amphetamine in a temporal discrimination procedure: Selective changes in timing or rate dependency? Journal of the Experimental Analysis of Behavior, 78, 195-214.

Odum, A. L., \& Schaal, D. W. (2000). The effects of morphine on fixed-interval patterning temporal discrimination. Journal of the Experimental Analysis of Behavior, 74, 229-243.

Pitts, R. C., \& Febbo, S. M. (2004). Quantitative analyses of methamphetamine's effects on selfcontrol choices: Implications for elucidating behavioral mechanisms of drug action. Behavioural Processes, 66, 213-233.

Plowright, M. S., Church, D., Behnke, P., \& Silverman, A. (2000). Time estimation by pigeons on a fixed interval: The effect of pre-feeding. Behavioural Processes, 52, 43-48. 
Roberts, S. (1981). Isolation of an internal clock. Journal of Experimental Psychology: Animal Behavior Processes, 7, 242-268.

Schneider, B. A. (1969). A two-state analysis of fixed-interval responding in the pigeon. Journal of the Experimental Analysis of Behavior, 12, 677-687.

Skinner, B. F. (1938). The behavior of organisms. New York: Appleton-Century-Crofts.

Staddon, J. E. R., Chelaru, I. M., \& Higa, J. J. (2002). A tuned-trace theory of interval-timing dynamics. Journal of the Experimental Analysis of Behavior, 77, 105-124.

Stubbs, A. (1968). The discrimination of temporal duration by pigeons. Journal of the Experimental Analysis of Behavior, 11, 223-238.

Zeiler, M. D. \& Powell, D. G. (1994). Temporal control in fixed-interval schedules. Journal of the Experimental Analysis of Behavior, 61, 1-10. 


\section{Mirari Elcoro}

\section{Curriculum Vitae \\ December, 2005}

\section{Personal Information}

Psychology Department

West Virginia University

53 Campus Drive

1124 Life Sciences Building

Morgantown, WV 26505-6040
E-Mail:Mirari.Elcoro@mail.wvu.edu

\section{Education}

12/05-current West Virginia University

Ph.D. student.

Behavior Analysis Program.

Adviser: Kennon A. Lattal

8/03-12/05 West Virginia University

M.S., Behavior Analisis

Thesis: Temporally Controlled Behavior to Change

Adviser: Kennon A. Lattal

10/95-10/00 Universidad Catolica Andres Bello(Caracas, Venezuela)

Lincenciado, Psychology

Thesis: A Cross-Species Study in Behavioral Timing

\section{Publications}

Anderson, K. G. \& Elcoro, M. (manuscript in preparation). Response Acquisition with Delayed Reinforcement in Lewis and Fischer 344 rats.

Lattal, K. A., Elcoro, M. \& daSilva, S. P. (manuscript in preparation). Visual Reinforcement in Female Betta splendens.

\section{Research Experience}

07/05-08/05 \& 08/04-12/05 Graduate Research Assistant. Department of Psychology. Behavioral Pharmacology Laboratory. West Virginia University. Supervised by Principal Investigator, K.G. Anderson, Ph.D. Activities included coordination of experimental routines and undergraduate research assistants. Programming experimental procedures with medpc and data analyses.

09/01-06/03 Research Staff Associate. Temporal Cognition Laboratory, Columbia University Biopsychology Division of the Psychiatry Department_\&_New York State Psychiatric Institute, New York, NY. Supervised by Principal Investigator, Chara Malapani, MD, Ph.D. Basic timing processes and their relations with neurological disorders. Operant conditioning and pharmacology experiments with mice. Data analysis. 
Written and oral presentation of results. Setup and adjustments of operant equipment. Training students in experimental routines.

01/00-10/00 Research Assistant. Classical and Operant Conditioning Laboratory

Universidad Central de Venezuela. Operant conditioning, data collection and analysis.

\section{Presentations}

Elcoro, M., \& Lattal, K. A. (2005, October). Resistance of Temporally Controlled Behavior to Change. Poster session presented at the Annual Meeting of the Southeastern Association for Behavior Analysis, Wilmington, NC.

Elcoro, M., \& Anderson K. G. (2005, May). Response Acquisition with Delayed Reinforcement in Lewis and Fischer 344 rats. Poster session presented at the Annual Convention of Association for Behavior Analyisis, Chicago, IL.

Elcoro, M., daSilva, S. P., \& Lattal, K. A. (2005, May). Visual Reinforcement in Female Betta splendens. Poster session presented at the Annual Convention of Association for Behavior Analyisis, Chicago, IL.

Elcoro, M. \& Lattal, K. A. (2004, October). Visual Reinforcement in Female Betta Splendens. Poster session presented at the Annual Meeting of the Southeastern Association for Behavior Analysis, Charlotte, NC.

Elcoro, M., Fairhurst, S., Towey, S.,Brunner, D., Gingrich, J. A. \& Malapani, C. (2003, May).Towards the Development of an Animal Model to Study Temporal Cognition in the Dopamine-Depleted Basal Ganglia. Poster session presented at the Annual Meeting of the Cognitive Neuroscience Society, New York, NY.

Bejar, L., Elcoro, M., Lira, A., \& Gingrich, J.A. (2002, July). The Role of the Serotonin 5-HT-2A Receptor in Neural Impulsivity in Mice as Observed in a DRL-15 Paradigm. Poster session presented at the Annual Meeting of Summer Undergraduate Research Fellowship, Biological Sciences Department at Columbia University, New York, NY.

Elcoro, M., \& Vargas-Irwin, C. (2001, May). A Cross-Species Study in Behavioral Timing. Paper presented at the Annual Convention of the Association for Behavior Analysis, New Orleans, LA.

Elcoro, M., \& Vargas-Irwin, C. (2000, November). Comparative Study of Behavioral Timing in WKY rats and Columba fasciata pigeons. Paper presented at the annual convention of the Venezuelan Association for the Advancement of Science, Caracas, Venezuela.

Vargas-Irwin, C., \& Elcoro, M. (2000, May). Effects of Delay of Reinforcement Over Behavioral Timing. Poster session presented at the Annual Convention of the Association for Behavior Analysis, Washington, DC. 


\section{Teaching Experience}

08/04-current Graduate Teaching Instructor. Department of Psychology. Behavior Principles. (PSYC 302). West Virginia University. Supervised by M. Perone, Ph.D. Laboratory instructor, supervision of experimental routines and grading reports.

08/05-12/05 Graduate Teaching Instructor. Department of Psychology. Introduction to Psychology (PSYC101). West Virginia University. Supervised by C. A.Anderson, Ph.D. Responsible for organization and presentation of lectures.

10/99-07/00 Teaching Assistant. Experimental Psychology, Animal Behavior Laboratory. Universidad Catolica Andres Bello, Caracas, Venezuela. Taught principles of psychopharmacology in animal behavior to third year students of Psychology. In charge operant conditioning laboratory, preparation, and evaluation of experiments, tests and final papers.

\section{Awards}

05/05-05/06 Doctoral Stipend Enhancement Fellowship, West Virginia University. 04/05-04/06 \& 10/03-10/04 Alumni Fund Grant Program, Department of Psychology, West Virginia University.

08/03-05/05 HERF Supplementary Fellowship, Department of Psychology, West Virginia University.

\section{Affiliations}

The Leakey Foundation

Association for Behavior Analysis (ABA) 